\title{
Determinantes espaciais e socioeconômicos do suicídio no Brasil: uma abordagem regional
}

\author{
Ludmilla R. C. Gonçalves \\ Mestre em Economia pela UFJF \\ Eduardo Gonçalves \\ Professor da UFJF e Pesquisador do CNPq \\ Lourival Batista de Oliveira Júnior \\ Professor da UFJF
}

\section{Palauras-chave \\ mortalidade, taxas de suicídio, econometria espacial, Brasil.}

\section{Classificação JEL I00, I12, Z13.}

\section{Keywords \\ mortality, suicide rates, spatial econometrics, Brazil.}

JEL Classification IOO, I12, $Z 13$.

\section{Resumo}

A Organização Mundial da Saúde avalia o suicídio como um problema de saúde pública, estando entre as dez causas mais frequentes de morte, além de ser a segunda ou terceira causa de morte entre 15 e 34 anos de idade. Estimativas mostram que para cada suicídio, existem pelo menos dez tentativas suficientemente sérias que exigem atenção médica e para cada tentativa de suicídio registrada, existem quatro não conhecidas. $\mathrm{O}$ objetivo desse artigo é avaliar os determinantes socioeconômicos das taxas de suicídio por microrregiões brasileiras, levando em consideração aspectos espaciais do problema. A hipótese desse artigo é que existe um "efeito contágio" espacial para o suicídio, ou seja, as taxas de suicídio dos vizinhos de uma microrregião são importantes determinantes do comportamento dessa variável em outra microrregião. Para tal, são usadas técnicas de econometria espacial que permitem avaliar se existe dependência espacial entre as taxas de suicídio das microrregiões.

\section{Abstract}

Suicide is considered a public health issued by the World Health Organization. Suicide is amongst the ten most frequent causes of death in all ages, in addition to being the second or third cause of death between 15 and 34 years of age. Estimates show that for every suicide there are at least ten suicides attempts that require medical attention and for every suicide attempt recorded, four are not known. The aim of this paper is to analyze the socioeconomic determinants of suicide rates for Brazilian micro-regions, taking into account spatial aspects of the problem. The hypothesis of this paper is that there is a "spatial contagion effect" for suicide, that is to say, the neighborhood suicide rates are an important determinant of the regional suicide rate. This is achieved by the use of spatial econometrics techniques to assess whether there is spatial dependence for suicide rates in micro-regions. 


\section{1_Introdução}

Nos últimos 45 anos, houve aumento de $60 \%$ da mortalidade por suicídio; portanto, ao longo desse período, o suicídio tem se mostrado um problema de saúde pública. Na maioria dos países, o suicídio situa-se entre as dez causas mais frequentes de morte e entre as duas ou três mais frequentes em adolescentes e adultos jovens. O Gráfico 1 apresenta o comportamento da taxa de suicídio para o ano de 2000, em países desenvolvidos. Nota-se que Japão, Áustria, Suíça e França são líderes em casos de suicí- dio, predominantemente masculinos. De acordo com registros da Organização Mundial da Saúde, 900.000 pessoas cometeram suicídio em 2003, representando uma morte a cada 35 segundos. Para cada óbito por suicídio, há no mínimo cinco ou seis pessoas próximas ao suicida cujas vidas são profundamente afetadas emocional, social e economicamente (OMS, 2000).

Do ponto de vista econômico, o suicídio e suas tentativas representam enorme custo para a sociedade. Primeiro, porque demanda recursos públicos

\section{Gráfico 1_ Taxa de suicídio por 100 mil habitantes em países desenvolvidos (2000)}

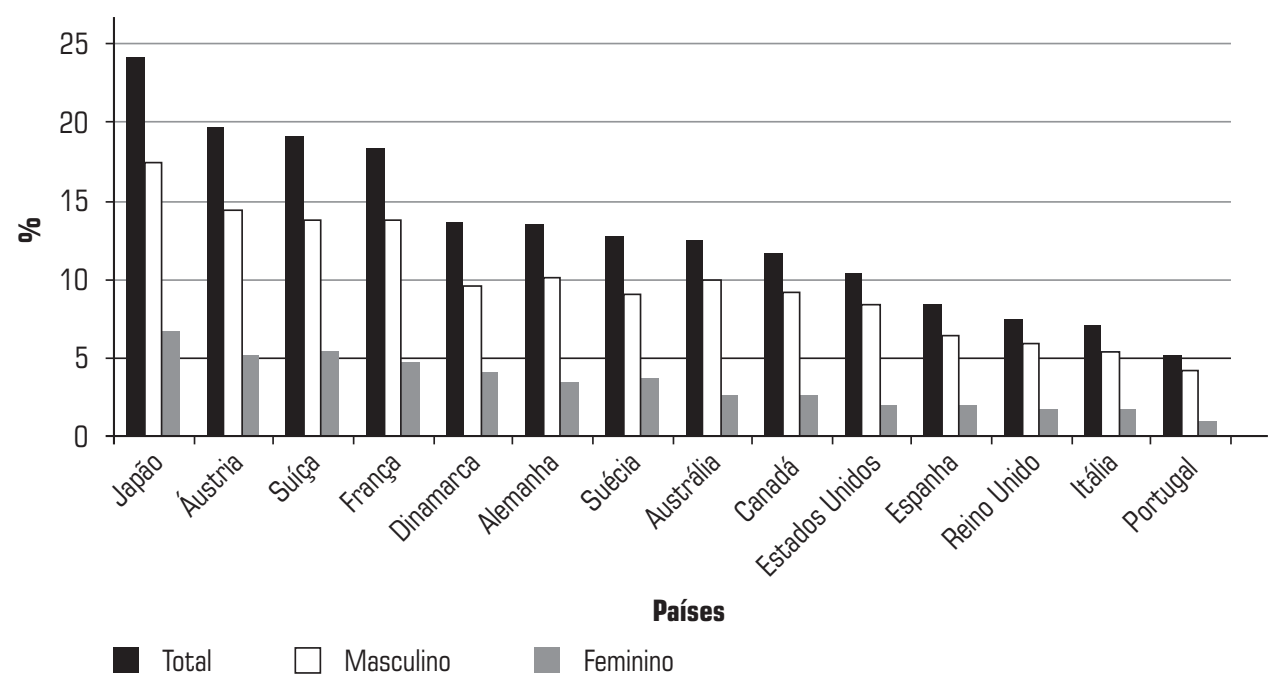

Fonte: Elaboração própria, com base nos dados do sítio do OMS (2008). 
1 Do inglês "disabilityadjusted-life-years” (DALYs). que poderiam estar sendo alocados de forma diferente; segundo, porque envolve significativa perda de capital humano. No estudo realizado pelo IPEA (2007), o valor médio das internações registradas como lesões autoprovocadas intencionalmente entre 1998-2004 é de R\$ 507. A média de permanência por internação no período foi de quatro dias, e a taxa de mortalidade, de $3,70 \%$ dos casos.

De acordo com a Organização Mundial de Saúde (2000), o custo do suicídio, estimado em termos de anos de vida ajustados às limitações ${ }^{1}$, representou $1,8 \%$ do gasto total com doenças em todo o mundo, em 1998. Isso equivaleu ao dispêndio com guerras e homicídios, sendo similar aos custos de internação por trauma e asfixia neonatal e o dobro do custo com diabetes. Na Suíça, das 30 mil pessoas que tentaram se suicidar, 1.350 conseguiram atingir esse objetivo. Os custos são estimados em US $\$ 1,8$ bilhão, dos quais cada tentativa representa US\$ 57 mil (Swissinfo, 2008).

A perda de capital humano também possui estimativa alta. No Brasil, Cerqueira et al. (2007) afirmam que o suicídio acarretou perda total de $\mathrm{R} \$ 1,3$ bilhão para o ano de 2001. Em termos de valores médios de perda de capital humano, os suicídios custam R $\$ 163$ mil por víti- ma, enquanto os homicídios e os acidentes de trânsito apresentam médias de $\mathrm{R} \$$ 189,5 mil e R $\$ 172$ mil, respectivamente.

Embora o problema do suicídio seja mais grave nos países desenvolvidos, há muitos países em desenvolvimento com taxas elevadas. No Gráfico 2, verifica-se que países como a República Checa e a Polônia possuem proporções de suicídios somente inferiores ao Japão, à Áustria, à Suíça e à França. O Brasil, ainda que tenha menores taxas de suicídio entre os países emergentes, apresenta tendência de agravamento do problema. De 1980 a 2002, ocorreram 125.707 suicídios, o que fornece uma média anual de 5.465. Já pelo Gráfico 3, é possível observar que há crescimento dos casos de suicídio entre 1980 e 2002. A maior parte das ocorrências é do sexo masculino, com participação média de $76 \%$ no período (OMS, 2008).

No Brasil, raros são os trabalhos que exploram esse campo da teoria econômica. Como exemplo, há o estudo de Shikida et al. (2006), que procura analisar como variáveis econômicas influenciam as taxas de suicídio por estados brasileiros. Os autores verificam que as macrorregiões Sul e Centro-Oeste se destacam em relação às demais. Meneghel et al. (2004) avaliaram séries históricas de 
Gráfico 2_ Taxa de suicídio por 100 mil habitantes em países emergentes (2000)

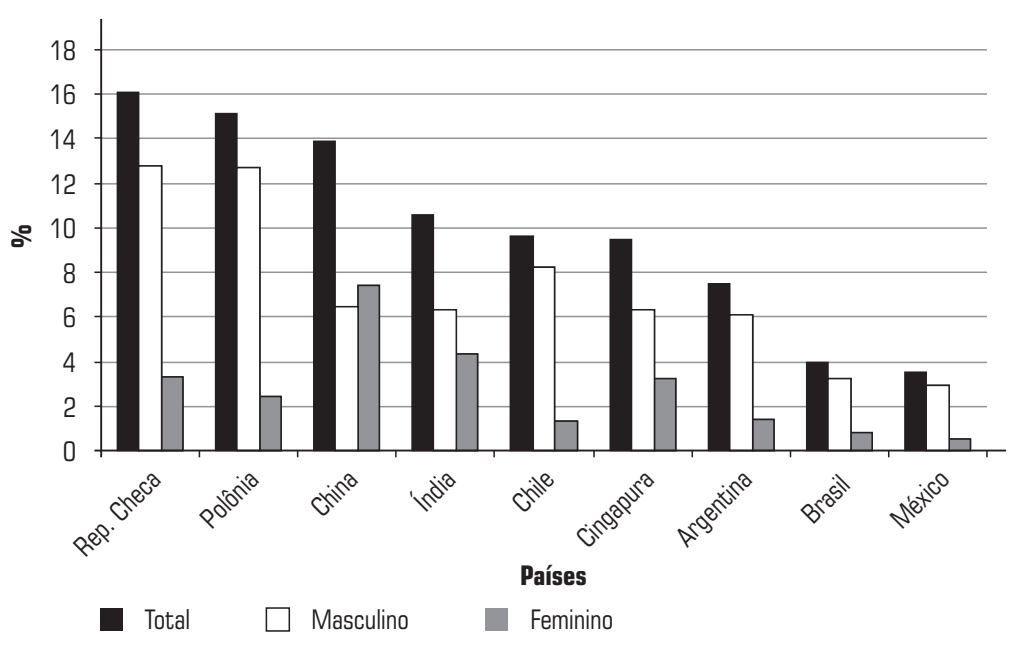

Fonte: Elaboração própria, com base nos dados do sítio do OMS (2008).

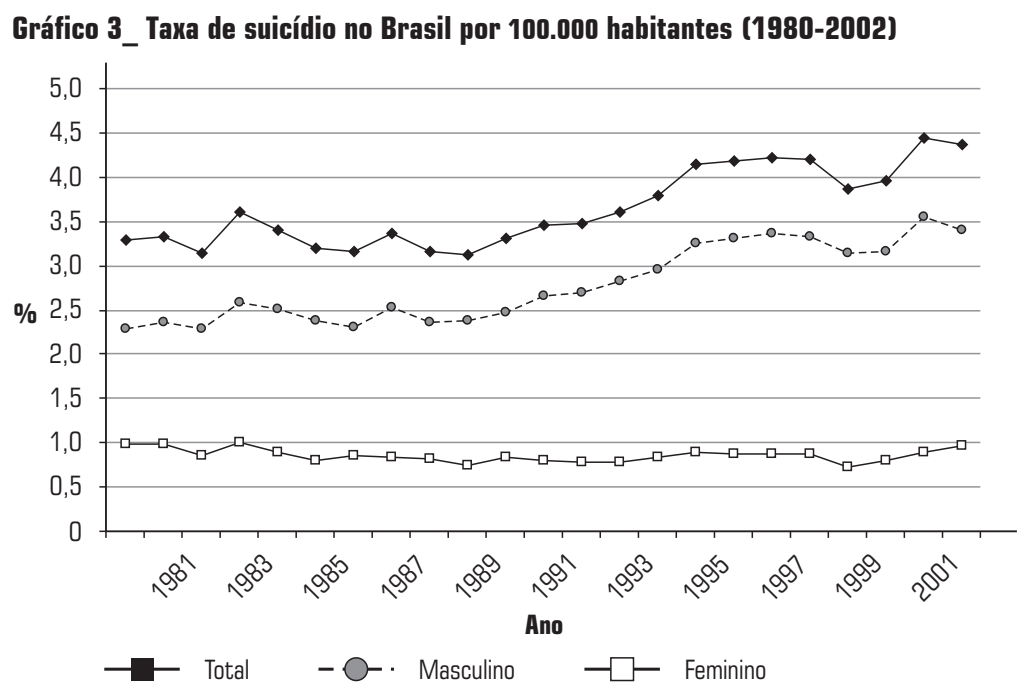

Fonte: Elaboração própria, com base nos dados do sítio do IPEA (2008). 
mortalidade por suicídio no Rio Grande do Sul e mostraram que o problema refletia precárias condições de sobrevivência, como o endividamento, a concentração da terra, o êxodo ou a exposição profissional intensa aos agrotóxicos. Os agrotóxicos podem acarretar quadros depressivos desencadeados por mecanismos neurológicos ou endócrinos. Pires et al. (2005) também alcançaram conclusão semelhante para a microrregião de Dourados, no Mato Grosso do Sul. Neste caso, a cultura algodoeira expunha os trabalhadores rurais aos agrotóxicos. No estudo do registro de óbitos por suicídio no IML de Palmas (Tocantins) realizado por Oliveira (2004), entre 2001 a 2004, o autor encontra que a maior parte das vítimas que cometeram suicídio são lavradores, com 33\% de participação.

Em que pese à importância de trabalhos como esses, várias lacunas ainda precisam ser preenchidas. A primeira delas é a ausência, tanto na literatura internacional quanto na nacional, de aplicação de métodos como Econometria Espacial. Ao focar os aspectos espaciais de uma distribuição de dados, a Análise Exploratória de Dados Espaciais (AEDE) permite descrever padrões de associação espacial (clusters espaciais), identificar diferentes regimes e formas de insta- bilidade espaciais, além de observações atípicas (outliers). Isso é particularmente importante para o problema do suicídio porque existe o que a literatura denomina de "efeito contágio", no qual o ato de atentar contra a própria vida, quando provocado por um indivíduo, pode afetar o comportamento de outros indivíduos sob as mesmas condições psicológicas e socioeconômicas. A dependência espacial também parece caracterizar distribuições de dados como as de suicídio, uma vez que ela ocorre em todas as direções, mas é inversamente relacionada à distância geográfica.

\section{Determinantes socioeconômicos do suicídio: uma revisão da literatura}

Historicamente, o suicídio tem sido relatado desde os primórdios da humanidade, sendo ora condenado, ora tolerado, dependendo da sociedade e do período em que estava inserido. Na Grécia antiga, por exemplo, um indivíduo não podia se matar sem prévio consenso da comunidade, por ser um atentado contra a estrutura comunitária. Em Roma, como em Atenas, o suicídio era legitimado apenas para níveis sociais mais elevados. $\mathrm{Na}$ Idade Média, o suicídio foi condena- 
do pela Igreja e pelo Estado, que igualavam os suicidas a ladrões e assassinos (Valério, 2006).

Atualmente, esse fenômeno assumiu caráter clandestino ou patológico, usado como método para atentados terroristas por, principalmente, fanáticos religiosos. O código penal brasileiro também condena a indução ou o auxílio ao ato suicida. A eutanásia, vista como suicídio assistido, é uma questão em discussão. Na cultura ocidental, o suicídio é pouco divulgado, constituindo-se em uma espécie de tabu (Brandão, 2008).

Tentativas de se explicar o suicídio não são recentes. Nas teorias sociais, Emile Durkheim foi um dos primeiros estudiosos a tentar procurar padrões para a taxa de suicídio. Durkheim publicou em 1897 a obra intitulada "Le Suicide", na qual analisou empiricamente os suicídios ocorridos no século XIX, na França. Subsequentemente, diversos outros autores se propuseram a explicar os determinantes do suicídio. Entretanto, os estudos diferem quanto às variáveis independentes, método, período e abrangência geográfica (ver Quadro 1).

Durkheim (2003, p. 15) discute a definição de suicídio com base na intenção do indivíduo em cometê-lo. Inicialmente, o define como todo o caso de morte que resulta direta on indiretamente de um ato positivo ou negativo praticado pela própria vítima e a tentativa de suicídio é 0 ato assim definido, mas interrompido antes que dele resulte a morte

Segundo o autor, o suicídio não é apenas um ato individual que depende exclusivamente de fatores pessoais que se situam unicamente no campo da Psicologia, ou seja, o estudo conjunto dos suicídios cometidos em determinada sociedade, durante dada unidade de tempo, tem natureza própria e é eminentemente social.

Segundo Durkheim (2003), o suicídio não é hereditário, o que se transmite de pai para filho é tão somente certo temperamento que pode predispor os indivíduos para o suicídio, mas que não pode constituir uma explicação da determinação desses. Portanto, o que se transmitia não seria a afecção propriamente dita, mas um ambiente favorável ao desenvolvimento. Além disso, a igualdade entre as raças também enfraquece a afirmação de hereditariedade como fator do suicídio. No entanto, de acordo com Kaplan e Sadock (1997), a taxa de suicídios entre os brancos foi duas vezes maior do que entre não brancos, em 1989, nos Estados Unidos. Em 1992, essa diferença diminui, ou seja, a taxa de sui- 


\section{Quadro 1_Pesquisas para a relação entre suicídio e aspectos socioeconômicos}

(continua)

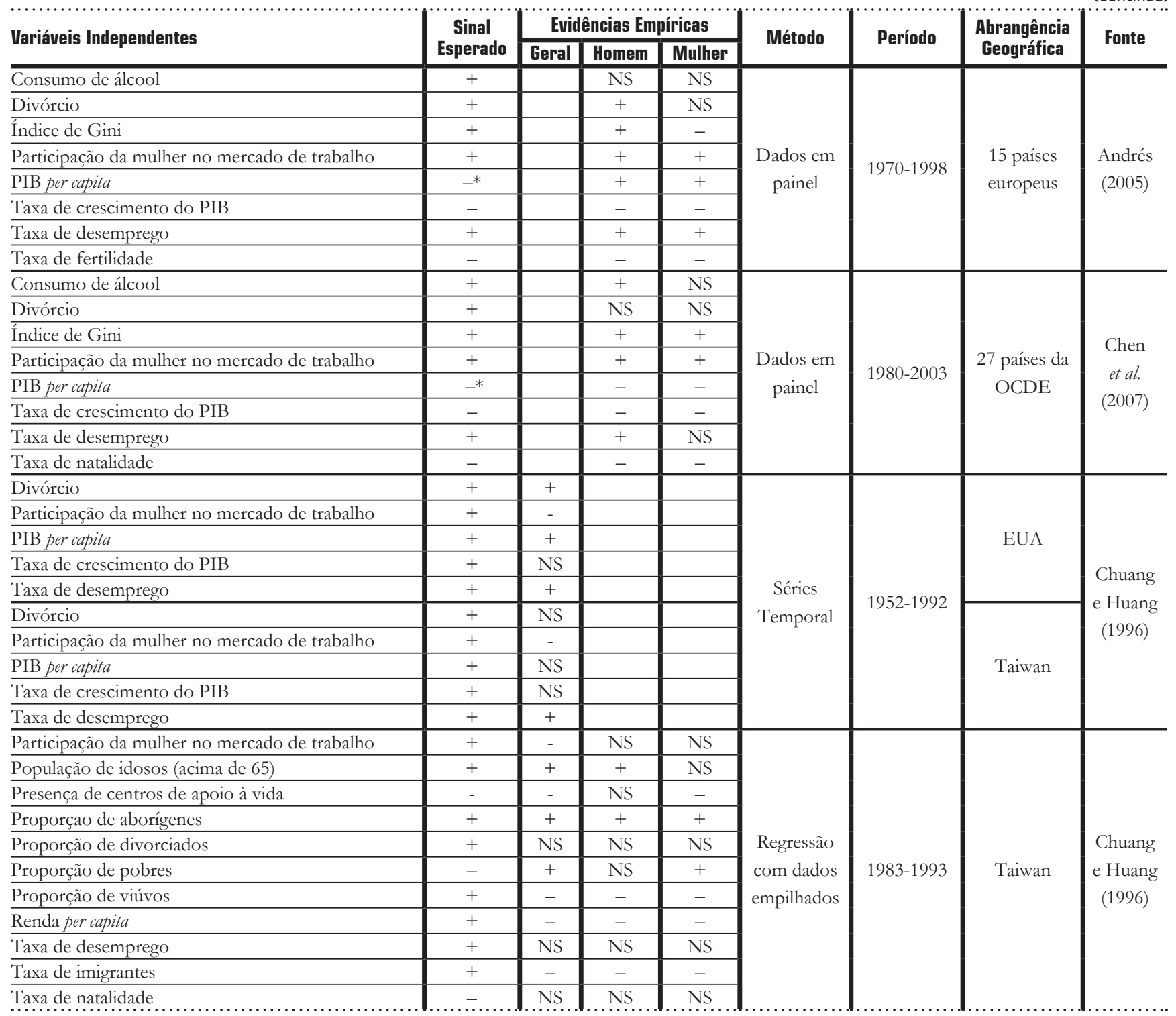


Quadro 1_Pesquisas para a relação entre suicídio e aspectos socioeconômicos

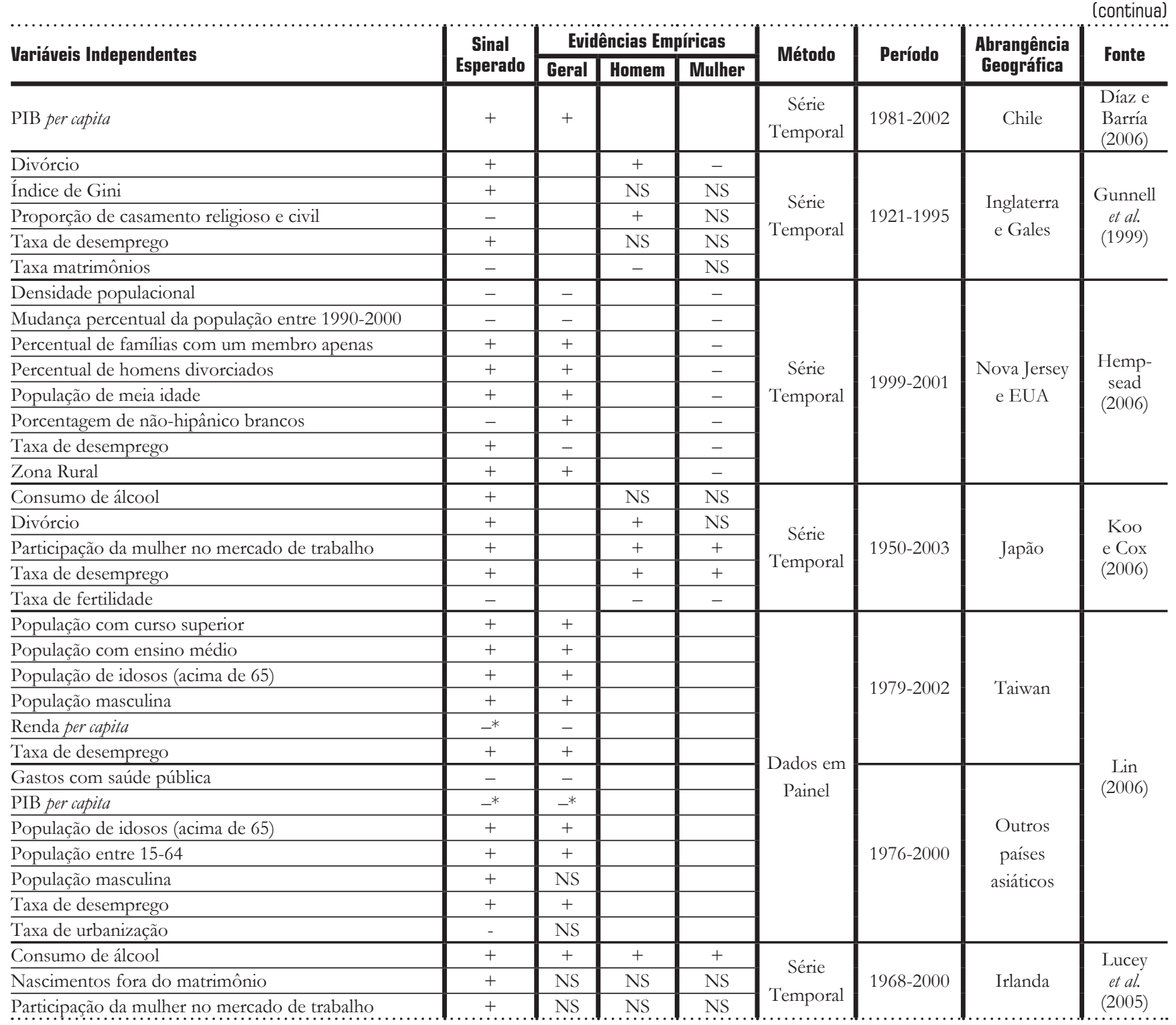


Quadro 1_Pesquisas para a relação entre suicídio e aspectos socioeconômicos

\begin{tabular}{|c|c|c|c|c|c|c|c|c|}
\hline \multirow{2}{*}{ Variáveis Independentes } & \multirow{2}{*}{$\begin{array}{c}\text { Sinal } \\
\text { Esperado }\end{array}$} & \multicolumn{3}{|c|}{ Evidências Empíricas } & \multirow{2}{*}{ Método } & \multirow{2}{*}{ Período } & \multirow{2}{*}{$\begin{array}{c}\text { Abrangência } \\
\text { Geográfica }\end{array}$} & \multirow{2}{*}{ Fonte } \\
\hline & & Geral & Homem & Mulher & & & & \\
\hline Taxa de criminalidade & + & + & + & + & \multirow{3}{*}{$\begin{array}{c}\text { Série } \\
\text { Temporal }\end{array}$} & \multirow{3}{*}{$1968-2000$} & \multirow{3}{*}{ Irlanda } & \multirow{3}{*}{$\begin{array}{l}\text { Lucey } \\
\text { et al. } \\
(2005)\end{array}$} \\
\hline Taxa de desemprego & + & NS & NS & NS & & & & \\
\hline Taxa de matrimônios & - & - & - & + & & & & \\
\hline Idade média da população & + & + & & & \multirow{3}{*}{$\begin{array}{c}\text { Série } \\
\text { Temporal }\end{array}$} & \multirow{3}{*}{ 1978-1994 } & \multirow{3}{*}{ Finlândia } & \multirow{3}{*}{$\begin{array}{l}\text { Matti } \\
(1998)\end{array}$} \\
\hline Razão mulher/homem & - & - & & & & & & \\
\hline Taxa de urbanização & + & + & & & & & & \\
\hline Densidade populacional & - & - & - & - & \multirow{8}{*}{$\begin{array}{c}\text { Dados em } \\
\text { Painel }\end{array}$} & \multirow{8}{*}{$1982-1997$} & \multirow{8}{*}{$\begin{array}{c}\text { Estados } \\
\text { Americanos }\end{array}$} & \multirow{8}{*}{$\begin{array}{l}\text { Minoiu } \\
\text { e Andrés } \\
\text { (2006) }\end{array}$} \\
\hline Divórcio & + & + & + & + & & & & \\
\hline Dummy para estados montanhosos & + & + & + & + & & & & \\
\hline Gastos com saúde pública & - & - & - & - & & & & \\
\hline Indice de Gini & + & NS & NS & NS & & & & \\
\hline Renda per capita & $-^{*}$ & NS & NS & NS & & & & \\
\hline Taxa de desemprego & + & NS & NS & NS & & & & \\
\hline Taxa de imigrantes & + & NS & NS & NS & & & & \\
\hline Razão mulher/homem & - & + & + & + & \multirow{6}{*}{$\begin{array}{c}\text { Dados em } \\
\text { Painel }\end{array}$} & \multirow{6}{*}{$1975-2001$} & \multirow{6}{*}{$\begin{array}{c}\text { Estados da } \\
\text { Índia }\end{array}$} & \multirow{6}{*}{$\begin{array}{l}\text { Mitra e } \\
\text { Shroff } \\
(2004)\end{array}$} \\
\hline Renda per capita & + & + & + & + & & & & \\
\hline Taxa de alfabetização & + & NS & NS & NS & & & & \\
\hline Taxa de crescimento do PIB & + & NS & NS & NS & & & & \\
\hline Taxa de desemprego & + & NS & NS & NS & & & & \\
\hline Taxa de urbanização & + & NS & NS & NS & & & & \\
\hline Medidas de redução do suicídio pela agência NYSPS & - & - & & & \multirow{3}{*}{$\begin{array}{c}\text { Série } \\
\text { Temporal }\end{array}$} & \multirow{3}{*}{$1966-2003$} & \multirow{3}{*}{ Austrália } & Morrel \\
\hline Taxa de desemprego de homens jovens $(20-24)$ & + & + & & & & & & et al. \\
\hline Taxa de desemprego de mulheres jovens (20-24) & + & NS & & & & & & $(2006)$ \\
\hline Consumo de álcool & + & + & NS & + & & & & \\
\hline Divórcio & + & NS & NS & NS & & & & \\
\hline Índice de Gini & + & NS & NS & NS & Dados em & & & Rodriguez \\
\hline Participação da mulher no mercado de trabalho & + & + & + & + & Painel & $194 /-2001$ & 40 paises & $(2006)$ \\
\hline PIB per capita & + & NS & NS & NS & & & & \\
\hline Taxa de fertilidade & - & NS & NS & - & & & & \\
\hline Gastos com saúde pública & - & NS & & & & & & \\
\hline IDH-Renda & - & + & & & Cross- & & Estados & Shikida \\
\hline Indice de Gini & + & NS & & & Section & 2000 & & $\begin{array}{c}\text { et al. } \\
(2006)\end{array}$ \\
\hline Jovens (18 a 24 anos) & - & - & & & & & & \\
\hline Divórcio & + & - & NS & NS & & & & Watanebe \\
\hline Taxa de desemprego & + & - & + & NS & Temnoral & $1970-2002$ & Japão & et al. \\
\hline 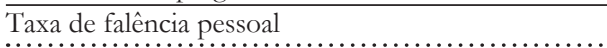 & + & $\ldots$ & + & $\begin{array}{l}+ \\
+\ldots\end{array}$ & $\begin{array}{l}\text { Temporal } \\
\ldots \ldots \ldots \ldots \ldots\end{array}$ & & & $\begin{array}{c}(2006) \\
\ldots \ldots\end{array}$ \\
\hline
\end{tabular}

* Artigo que segue a vertente de Hamermesh e Hoss (1974); NS = não significativo estatisticamente.

Fonte: elaboração própria a partir da revisão da literatura. Obs.: A variável dependente dos estudos é Taxa de Suicído por Habitantes. 
cídio entre brancos foi 1,6 vez superior à entre homens negros.

A teoria durkheimiana aponta uma relação positiva entre o aumento da idade e a taxa de suicídio. Para o autor, a velhice se caracteriza por ter o índice mais elevado de suicídio porque, nesse período, se vivem situações altamente desvitalizantes como: isolamento social, desemprego, aflições econômicas e perda de entes queridos. Matti (1998), em seu estudo para a Finlândia, mostra que, quanto maior a idade média da população, maior é o risco de suicídio. Esse resultado é confirmado por Lin (2006) e Chuang e Huang (1997) para pessoas acima de 65 anos. Hempstead (2006) encontra forte significância estatística para a população de meia idade.

De acordo com Durkheim (2003), a sociedade também exerce papel fundamental na construção do indivíduo. Fatores sociais, como a família, a escola, os grupos de que participa, os amigos e a sociedade, influenciam incisivamente na produção de um episódio suicida, tanto para que esse ocorra quanto para evitálo. Neste sentido, os indivíduos estão integrados em um grupo social, regulado por normas e convenções. Fatores que estreitam os laços familiares foram testados, como a taxa de fertilidade, que mostrou-se negativa e significativa para explicar o suicídio (Koo e Cox, 2006; Rodríguez, 2006 e Andrés, 2005). Por outro lado, divórcio e consumo de álcool representam fatores que diminuem a integração social. Para essa variável, Rodríguez (2006) encontrou sinal positivo e significativo para ambos os sexos. Chen et al. (2007) confirmaram essa hipótese apenas para o sexo masculino. Para Gunnell et al. (1999), Chuang e Huang (1996) e Minoiu e Andrés (2006), o divórcio aumenta o risco de suicídio. No entanto, para Koo e Cox (2006) e Andrés (2005), essa relação positiva apenas se confirma para o sexo masculino.

Durkheim (2003) descreveu vários tipos de suicídio, tendo em conta que, para haver tipos de suicídio diferentes, teriam também que existir causas diferentes. Assim, o autor classifica os suicídios de acordo com as causas sociais, tornando-se desta forma "[...] tipos sociais do suicídio [...]”. Entre esses, estão, o suicídio egoísta, que acontece quando o nível de integração social é baixo, levado pelo isolamento e depressão; o suicídio altruísta, quando o indivíduo encontra-se demasiadamente integrado na sociedade, levado por lealdade a uma causa; e o suicídio anômico, que está relacionado a paixões propriamente individuais. 
Durkheim (2003) argumenta que a educação, assim como a fraca religiosidade, está associada a um nível mais elevado de suicídio por embutir no indivíduo um sentimento maior de independência. Lin (2006) apresenta um estudo em dados em painel para Taiwan e mostra que, para o sexo masculino, quanto maior for o grau de instrução, maior será o risco de suicídio, argumentando que o trabalho de pessoas com alta escolaridade pode ser mais estressante. Ao ser submetido a maior estresse mental, o indivíduo teria maior probabilidade de suicídio. Mitra e Shroff (2006) encontram relação positiva, embora não significativa, entre taxa de alfabetismo e suicídio para a Índia.

O fato de os homens, em geral, serem mais instruídos do que as mulheres faz com que estas tenham taxas de suicídios mais baixas. Nas últimas décadas, essa diferença educacional tem se reduzido. No entanto, a menor ocorrência de suicídio entre as mulheres tem sido atribuída à baixa prevalência de alcoolismo; à religiosidade; às atitudes flexíveis em relação às aptidões sociais e ao desempenho de papéis durante a vida. Além disso, as mulheres reconhecem precocemente sinais de risco para depressão, buscando ajuda em momentos de crise e participando das redes de apoio social.
A maior taxa de participação das mulheres no mercado de trabalho tem acirrado a competitividade entre sexos, corroborando o aumento da taxa de suicídio segundo diversos autores (Andrés, 2005; Chen et al., 2007; Koo e Cox, 2006; Rodríguez, 2006). No entanto, Chuang e Huang (1996 e 1997) encontram um resultado controverso para esse tema.

Comportamentos que predispõem ao suicídio, como competitividade, impulsividade e maior acesso a tecnologias letais e armas de fogo, são mais comuns no universo masculino. A falência em cumprir os tradicionais papéis de gênero, o que significa constituir-se como provedor econômico da família, é grande fator de estresse para o homem. Inseridos na cultura patriarcal, os homens são mais sensíveis a reveses econômicos como desemprego e, por isso, mais propensos ao suicídio (Meneghel et al., 2004).

A maior proteção contra o suicídio, segundo Durkheim, é a estreita convivência entre religião, família e sociedade. Para ele, educação e renda levam ao aumento da independência individual, expondo o indivíduo a um maior risco de cometer suicídio. Da mesma forma, desastres naturais, crises econômicas ou guerras também contribuem para o aumento do suicídio, uma vez que re- 
presentam grande distúrbio da ordem social. Essa volatilidade na renda ocasionada pelas crises econômicas influencia diretamente o aumento da taxa de suicídio. A associação positiva entre desemprego $^{2}$ e suicídio foi confirmada pelos trabalhos de Koo e Cox (2006), Andrés (2005), Lin (2006) e Chuang e Huang (1996). Chen et al. (2007), Watanabe et al. (2006) e Morrell et al. (2007) encontraram essa relação positiva apenas para suicidas do sexo masculino, e neste último, apenas entre jovens.

Com relação a distúrbios de ordem natural e com base em dados municipais dos anos 80, Krug et al. (1998) encontraram relação positiva entre suicídio e ocorrências de terremotos, inundações e furacões. Entretanto, Shoaf et al. (2004) também utilizam dados municipais para mostrar que os efeitos causados pelo terremoto Northridge, na Califórnia, em 1994, não culminaram em aumento da taxa de suicídio. Ambos os trabalhos utilizaram método de estatística descritiva.

De acordo com a teoria econômica do suicídio de Hamermesh e Hoss (1974), quanto maior a renda esperada, mais alto será o nível de consumo e de satisfação e menor será o risco de suicídio. Estudos utilizando dados em painel feitos para países da Organização para
Cooperação e Desenvolvimento Econômico (OCDE) confirmaram tal hipótese (Lin, 2006 e Chen et al., 2007). Em contraste, para Durkheim, a renda elevada favorece a taxa de suicídio por aumentar a independência pessoal e a consequente degeneração familiar, sendo o chamado "suicídio egoísta". Muitos autores confirmaram essa hipótese por meio de diferentes metodologias e regiões: Mitra e Shroff (2006) e Andrés (2005) utilizaram dados em painel, respectivamente para a Índia e países europeus; Díaz e Barría (2006), com séries temporais para o Chile; e Shikida et al. (2006), com cross-section para estados brasileiros. Portanto, existem fortes evidências empíricas de que a hipótese de Durkheim seja a mais correta.

Apesar dos resultados divergentes para o nível de renda, a maioria dos estudos concorda com a hipótese de que desigualdade de renda eleva a taxa de suicídio. Chen et al. (2007) apresentam um modelo de dados em painel para justificar a relação causal entre desigualdade de renda e suicídio para ambos os sexos. Andrés (2005) só confirma essa relação para suicidas do sexo masculino.

De acordo com Durkheim (2003), as taxas de suicídio nas cidades são maiores se comparadas ao campo, enquan-

\footnotetext{
Inoue et al. (2007)

estudaram a correlação anual entre taxa de desemprego e taxa de suicídio no Japão, entre 1984 e 2003. Nesse trabalho constataram que há correlação positiva e significativa apenas para casos do sexo masculino.
} 
Bills e Li (2005) examinaram a correlação entre taxa de suicídio e homicídio em uma cross-section para 65 países. A análise por regiões geográficas revelou que, em países europeus, a correlação é positiva, mas negativamente correlacionada para países dos continentes asiático e americano. to as taxas de homicídio ${ }^{3}$ são maiores nas áreas rurais. Mitra e Shroff (2006) e Matti (1998) confirmam tal relação, embora o primeiro não seja estatisticamente significativo. Entretanto, estudos recentes realizados por Hempstead (2006), Lin (2006) e Minoiu e Andrés (2006) têm mostrado que esses padrões são inversos. Middleton et al. (2003) argumentam que umas das possíveis explicações para maiores taxas de suicídio no meio rural é o difícil acesso à rede de saúde e de serviços em geral. O declínio econômico, o aumento do desemprego e o êxodo rural também contribuem para esse quadro.

O efeito contágio do ato de suicidar também é abordado por Durkheim (2003). A hipótese principal do autor era que a imitação produz efeitos sociais, que, por sua vez, afeta a taxa social do suicídio. No entanto, os dados de suicídio por circunscrições francesas entre o período compreendido entre 1887 e 1891 não confirmaram essa hipótese, já que a taxa de suicídio alterou-se de forma radical entre regiões vizinhas, sempre que o meio social se modificava bruscamente. No entanto, algumas pesquisas posteriores, como a de Cutler et al. (2000), encontram evidências de efeito contágio entre jovens americanos que já tiveram expe- riências semelhantes entre familiares ou conhecidos próximos.

Dada a evidência relativamente inconclusiva da relação entre suicídio e imitação, abre-se espaço para estudos que levem em conta a dependência espacial, visto que, para Durkheim (2003), se essa influência existe, é sobretudo na distribuição geográfica dos suicídios que ela deve ser mais visível:

É provável que em certos casos se veja os tracos de um país ou de uma localidade se comunicarem, por assim dizer, as localidades vizinhas. É indispensável, pois, consultar um mapa, mas há que fazêe-lo com método (Durkheim, 2003, p.123).

O conhecimento, por intermédio da análise espacial dos eventos, permite a execução de ações e avaliação de intervenções dirigidas à prevenção e ao controle dos danos à saúde. A localização dos eventos no espaço permite a visualização da taxa de suicídio por região, tornando mais precisa a análise dos fatores que orientam e condicionam a definição das políticas públicas na área da saúde. Portanto, com a identificação das áreas geográficas e de seus fenômenos, é possível apontar grupos da população que apresentam as maiores taxas de suicídio e necessitam de atenção na prevenção. 
Na próxima seção, as variáveis usadas neste artigo são selecionadas e justificadas com base na revisão da literatura realizada acima.

\section{Bases de dados e aspectos metodológicos}

Este trabalho faz uso da base de dados de suicídio por microrregiões brasileiras, disponível no sítio do IPEA, cuja fonte primária é fornecida pelo Sistema Único de Saúde (SUS). Como as bases de dados disponíveis são referentes a regiões geográficas e não às características dos indivíduos, este artigo tentará identificar a influência de causas socioeconômicas sobre as taxas de suicídio de microrregiões geográficas brasileiras. Portanto, a variável dependente do estudo é a média da taxa de suicídio por 100.000 habitantes, que se refere ao período de 1998-2002.

A abordagem ecológica utilizada no neste estudo visa à análise dos dados de suicídio por microrregiões e possui algumas limitações inerentes ao método. Nos estudos ecológicos, a unidade de análise é a população, e não o indivíduo. Assim, uma importante limitação desses estudos é que a relação entre as duas variáveis não reflete necessariamente a situação dos indivíduos. Além disso, esse delineamento pode incorrer na chamada "falácia ecológica" (indevida generalização das características de um agregado, para as unidades que o compõem). No entanto, essa opção foi adotada uma vez que o sistema público de saúde a utiliza para a implementação de suas políticas.

Muitos são os fatores destacados pela literatura para explicar o suicídio, os quais podem ser citados: situação econômica, grau de desigualdade, gastos com saúde pública, região geográfica, idade e sexo do indivíduo, saúde mental, nível educacional, grau de urbanização, taxa de desemprego, problema de identidade sexual, exposição a armas de fogo, situações de perda, exposição a situações de estresse extremo (i.e., abuso sexual, instabilidade familiar) e histórico familiar.

$\mathrm{O}$ uso de indicadores varia de acordo com a disponibilidade de dados e com a necessidade de evitar a utilização simultânea de variáveis que sejam muito correlacionadas, a fim de evitar problemas como a multicolinearidade. Isso origina problemas de escolhas arbitrárias, podendo tornar os resultados sensíveis ao indicador escolhido. Nesse sentido, procurou-se incluir muitas variáveis que estivessem disponíveis nos bancos de dados públicos e que fossem relacionadas aos argumentos teóricos que ten- 
tam explicar as taxas de suicídio do ponto de vista socioeconômico, conforme a descrição a seguir:

X1: Percentual de pessoas com mais de 25 anos que são analfabetas em 2000 na microrregião (IPEA, 2009);

X2: Percentual de pessoas com mais de 25 anos que têm menos de quatro anos de estudo em 2000por microrregião (IPEA, 2009);

X3: Pessoas consideradas indigentes na microrregião, definido como percentual de pessoas com renda domiciliar per capita inferior a R\$ 37,75 , equivalentes a $1 / 4$ do salário mínimo vigente em agosto de 2000 (IPEA, 2009);

X4: Pessoas consideradas pobres na microrregião, definido como percentual de pessoas com renda domiciliar per capita inferior a $\mathrm{R} \$$ 75,50 , equivalentes a $1 / 2$ do salário mínimo vigente em agosto de 2000 (IPEA, 2009);

X5: Percentual da população com renda familiar inferior a 1 salário mínimo em 2000 na microrregião (PNUD, 2008);
X6: Índice de Gini microrregional, que mede o grau de desigualdade existente na distribuição de indivíduos segundo a renda domiciliar per capita (IPEA, 2009);

X7: Índice de Desenvolvimento Humano (IDH) por microrregião para o ano de 2000, calculado pelo Programa das Nações Unidas para o Desenvolvimento (PNUD), disponível no IPEA (2009);

X8: População total residente na área rural em relação ao total da população da microrregião, em 2000(IPEA, 2009);

X9: População economicamente ativa da área rural dividida pela população economicamente ativa total em 2000 por microrregião (IPEA, 2009);

X10: População ocupada rural da microrregião, definida como aquela que trabalhou nos últimos 12 meses anteriores à data de referência do Censo Demográfico, em 2000 (IPEA, 2009);

X11: Capital residencial rural da microrregião, definido pelo valor presente do fluxo perpétuo constante dos aluguéis mensais descontados à taxa de 0,75\% a.m., para o ano de 2000 (IPEA, 2009); 
X12: Número de instituições de curso superior por 100.000 habitantes de cada microrregião em 2000 (INEP/MEC, 2008);

X13: Número de concluintes de curso superior em relação à população jovem (18 a 24 anos) por 100.000 habitantes de cada microrregião em 1999 (INEP/MEC, 2008);

X14: Número de matriculados no ensino superior em relação à população jovem (18 a 24 anos) por 100.000 habitantes por microrregião em 2000 (INEP/MEC, 2008);

X15: Docentes na educação superior por 100.000 habitantes por microrregião em 2000 (INEP/ MEC, 2008);

X16: Número de eleitores do sexo feminino em relação ao total de eleitores da microrregião em 1998 (IBGE, 2002);

X17: Número de pessoas residentes do sexo feminino em relação ao total de residentes na microrregião em 1998 (IBGE, 2002).

Todos os indicadores descritos acima se referem aos anos 1998, 1999 ou 2000. A variável dependente refere-se à média do período 1998-2002. Embora as estatísticas de suicídios estejam disponíveis desde 1980, a tentativa desse modelo é a de explicar o suicídio do período recente. Isso porque as bases de dados que serviram para a construção das variáveis independentes estão disponíveis, com riqueza necessária e por microrregiões, apenas para os três anos mencionados. Os indicadores selecionados possuem a intenção de captar características estruturais das microrregiões que possam estar relacionadas ao fenômeno do suicídio. Além disso, não é possível haver problemas de bicausalidade no presente estudo por causa da característica da variável dependente usada, totalmente exógena ao modelo econométrico.

\section{4_Análise dos resultados}

\section{1_Análise exploratória de dados espaciais}

O propósito desta seção é explorar as características espaciais da variável dependente deste estudo, que é a taxa média de suicídio para o período compreendido entre 1998-2002. Com essa técnica, podemos detectar a existência de padrões de associação espaciais para as microrregiões brasileiras, as quais perfazem um total de 558. 
4 O I de Moran é calculado com base na matriz de contiguidade binária na convenção Queen, que considera como vizinhos as microrregiões de fronteira comum.
A análise exploratória de dados espaciais está baseada, principalmente, em duas ferramentas. A primeira é o $I$ de Moran, medida global de associação espacial. Ela serve para verificar se o agrupamento é uma tendência geral dos dados. A segunda é o indicador de associação local (LISA), que complementa a primeira porque mostra padrões de agrupamentos locais, mesmo quando indicadores globais não apresentam associação espacial (Anselin, 1992, 1995a e 1995b).

A título de comparação, na Tabela 1, estimou-se a estatística I de Moran para os anos compreendidos entre 19982002. Além disso, calculou-se o I de Moran para a média do período com o intuito de testar a significância estatística. Como podem ser observados, todos os valores de I de Moran são sempre positivos e significativos. Os resultados individuais são muito parecidos, uma vez que o I de Moran é sempre significativo e se situa entre 0,57 e 0,52 , justificando, portanto, o uso da média do período como variável dependente. ${ }^{4}$

O diagrama de dispersão de Moran apresentado na Figura 1A revela que não existem pontos a mais de dois desvios padrões do centro nos quadrantes BA e $A B$, não tendo, portanto, outliers espaciais. Na Figura 1B, os pontos de alavan- cagem são identificados pelos pontos em amarelo que estão a mais de dois desvios padrões do centro nos quadrantes AA e BB. Se essas microrregiões influentes forem excluídas da amostra, o I de Moran apresentaria grau de associação positiva maior, sendo igual a 0,7207 .

Os resultados descritos anteriormente podem ser visualizados na Figura 2, nos mapas de dispersão de Moran, os quais possibilitam ter uma ideia clara da dependência espacial. Cabe ressaltar que o regime AA se faz presente principalmente nas microrregiões das regiões Sul e Centro-Oeste.

Embora seja capaz de apontar a tendência geral de agrupamento dos dados, o I de Moran é uma medida global e por isso não revela padrões locais de associação espacial, ou seja, a estrutura regional de autocorrelação espacial. Portanto, o problema com o diagrama e o mapa de dispersão de Moran é que neles não há uma avaliação da incerteza estatística desses regimes espaciais $\mathrm{AA}, \mathrm{BB}$, $\mathrm{AB}$ e BA. Para isso, são construídas medidas de instabilidade local, sendo possível mapear os valores da probabilidade através dos indicadores locais de associação espacial (LISA) que são usados para testar a hipótese nula de distribuição aleatória por comparar os valores de cada 
Tabela 1_Teste de autocorrelação espacial para taxas de sucídio no Brasil - Período: 1998-2002

\begin{tabular}{|c|c|c|c|c|}
\hline Ano & I de Moran & Média & Desvio Padrão & Probabilidade \\
\hline 1998 & 0,5736 & $-0,0020$ & 0,0257 & 0,0001 \\
\hline 1999 & 0,5522 & $-0,0020$ & 0,0255 & 0,0001 \\
\hline 2000 & 0,5838 & $-0,0020$ & 0,0254 & 0,0001 \\
\hline 2001 & 0,5296 & $-0,0020$ & 0,0259 & 0,0001 \\
\hline 2002 & 0,5310 & $-0,0020$ & 0,0259 & 0,0001 \\
\hline Média 1998-2002 & 0,6975 & $-0,0020$ & 0,0256 & 0,0001 \\
\hline
\end{tabular}

* Pseudo-significância empírica baseada em 10.000 permutações

Fonte: elaboração própria com base no programa SpaceStat 1.91.

\section{Figura 1_ Diagrama de dispersão de Moran}

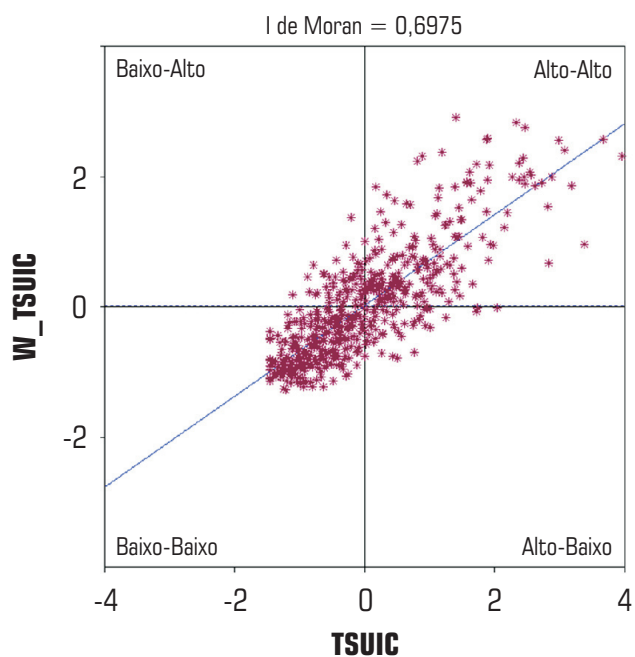

(a)

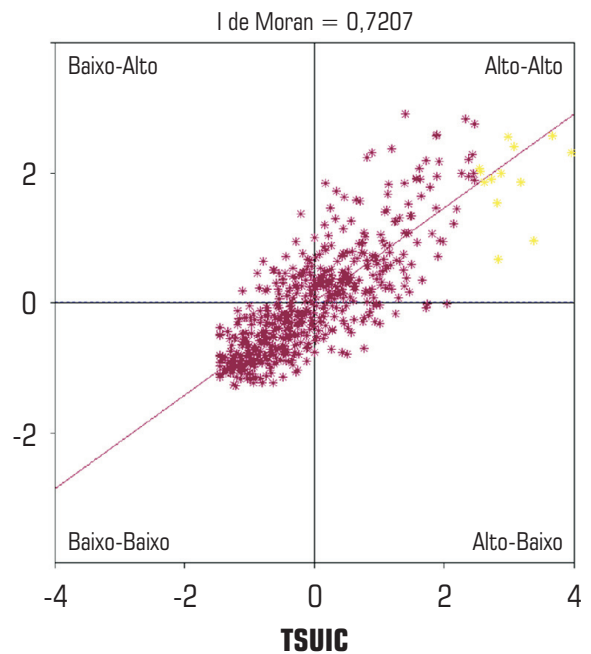

(b)

Fonte: Elaboração própria, com base no programa Geoda. 
Figura 2_ Mapa de dispersão de Moran para taxa média de suicídio (1998-2002)

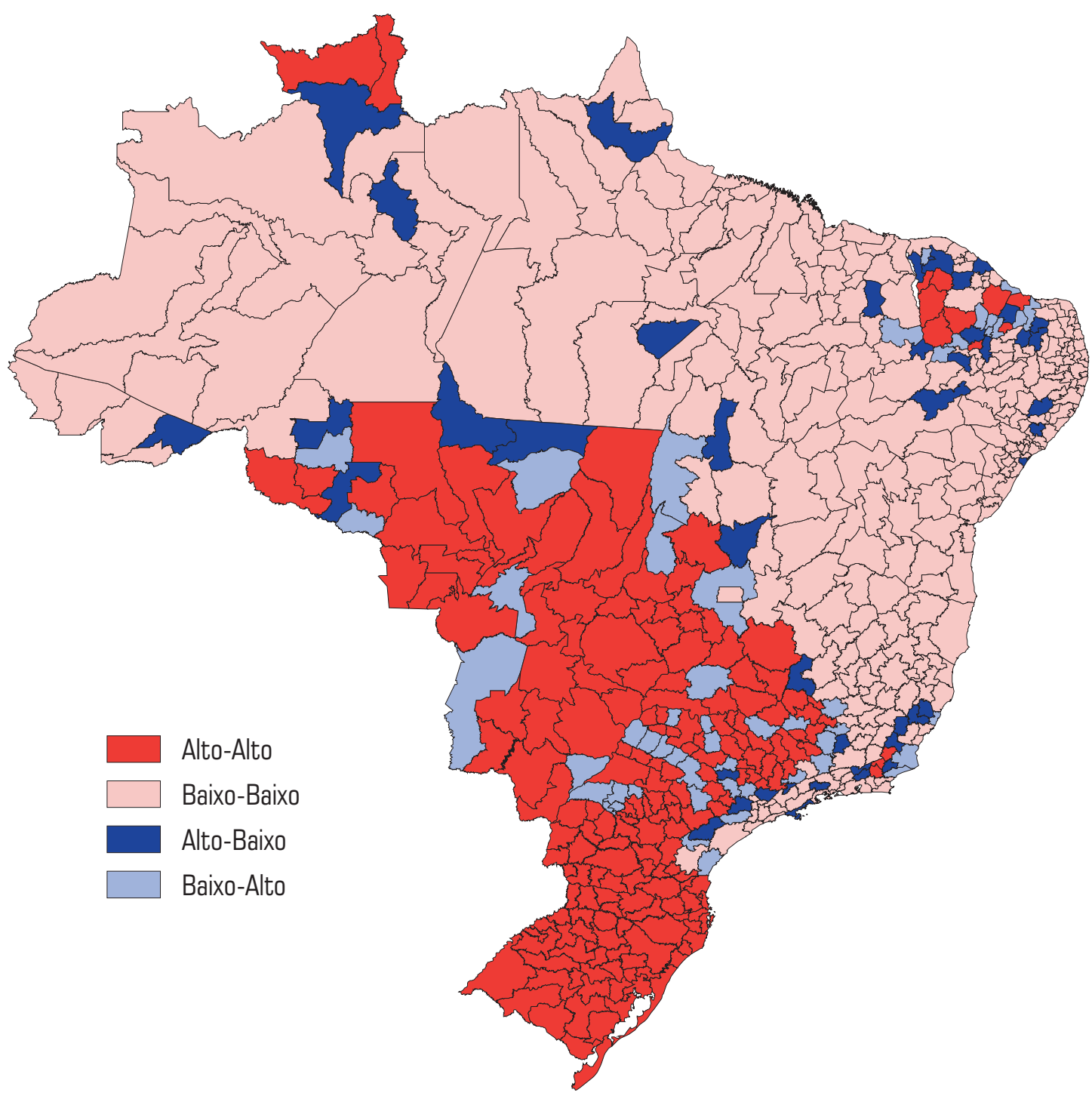

Fonte: Elaboração própria, com base no programa ArcView-GIS. 
localização específica com os valores de seus vizinhos.

A associação linear espacial localizada pelo $I_{i}$ de Moran é representada pelo mapa de significância e pelo mapa de cluster. Este último contém simultaneamente informações do mapa de dispersão de Moran e dados do mapa de significância das medidas de associação local I. Os mapas de cluster (Figura 3A) e significância (Figura 3B) mostram o predomínio do padrão de associação espacial
AA pra as regiões Sul e Centro-Oeste unicamente.

A próxima seção tem o objetivo de tratar e preparar as variáveis independentes para modelar os determinantes socioeconômicos da taxa de suicídio nas microrregiões brasileiras.

\section{2_Análise fatorial}

Nesta seção é realizada uma análise fatorial sobre os 17 indicadores socioeconômicos, definidos na seção metodológica,

\section{Figura 3_Padrões locais para a taxa média de suicídio (1998-2002)}
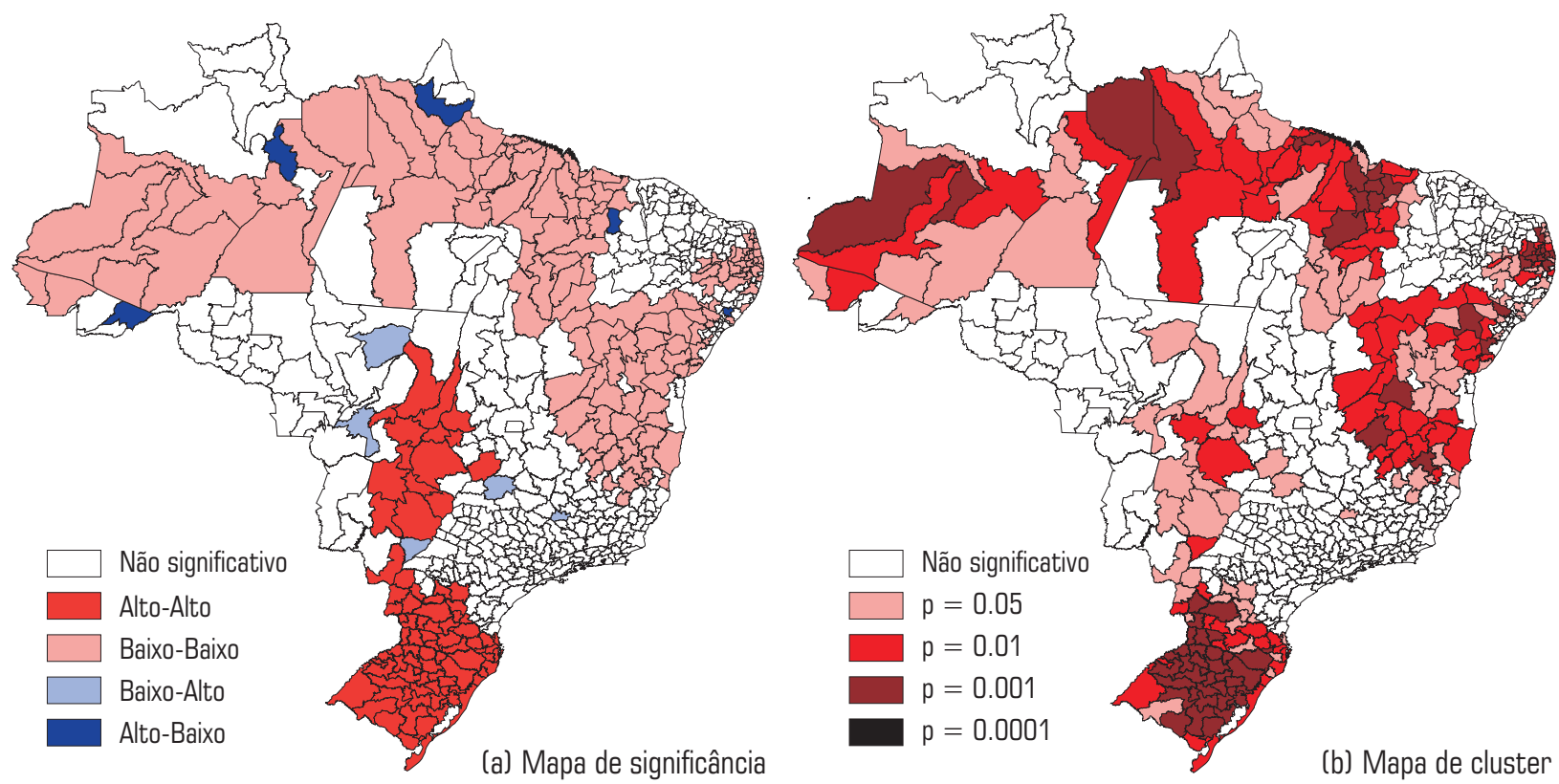

Fonte: Elaboração própria, com base no programa Geoda. 
Todos os 17 indicadores foram padronizados, de forma que passassem a ter média igual a zero e desvio padrão unitário.

6 Apenas foram apresentados os coeficientes com valor acima de 0,50 , para facilitar a visualização e a interpretação dos resultados. que são referentes a 558 microrregiões brasileiras, de acordo com a divisão territorial do país em 1998. A análise fatorial tem o objetivo de simplificar um conjunto de dados por meio de uma redução do número de variáveis que passam a ser expressas por fatores que são ortogonais entre si. $^{5}$

A primeira etapa da análise fatorial é expressa pela Tabela 2, que contém a medida de adequação dos dados de Kaiser-Meyer-Olkin (KMO). É possível notar que tal estatística possui valor de 0,89 , indicando boa adequação dos dados à análise fatorial (Pereira, 1999). O teste de esfericidade de Bartlett rejeita a hipótese nula de que a matriz de correlação seja uma matriz identidade.

A segunda etapa da análise fatorial envolveu a extração dos fatores iniciais pelo método de componentes principais, o que é recomendado quando as variáveis explicativas de uma equação possuem alto grau de correlação parcial. A Tabela 3 revela que quatro fatores têm raízes características que são superiores à unidade, seguindo recomendação de Manly (1986). Juntos, os quatro fatores explicam 89\% das variâncias das 17 variáveis socioeconômicas escolhidas. Entretanto, o fator mais importante é o definido como "pobreza", uma vez que sozinho explica quase $60 \%$ da variabilidade total do conjunto dos dados. $\mathrm{O}$ fator que menos explica é o quarto ("mulher'), $\operatorname{com} 6,47 \%$.

A terceira etapa foi o procedimento de rotação varimax, com o intuito de minimizar o número de variáveis com altas cargas num fator. Por meio dela, foi possível constatar que as variáveis X1 a X7 apresentaram forte relação com apenas o primeiro fator, tornando possível denominá-lo "pobreza" (Tabela 4). ${ }^{6}$ Outras quatro variáveis apresentam relação com o fator 2, que foi intitulado de

\section{Tabela 2_Testes de adequação da amostra à análise fatorial}

\begin{tabular}{|c|c|}
\hline Medida de Adequação da Amostra de Kaiser-Meyer-Olkin & 0,89 \\
\hline Teste de Esfericidade de Bartlett & \\
\hline Estatística $\chi^{2}$ & $19.266,21$ \\
\hline Graus de liberdade & 136 \\
\hline Probabilidade & 0,000 \\
\hline
\end{tabular}

Fonte: elaboração própria com base no programa SPSS 11.5 . 
Tabela 3_Raízes características e percentual de variância explicada pelos fatores

\begin{tabular}{c|c|c|c|c|c} 
Fator & $\begin{array}{c}\text { Indicadores que } \\
\text { definem os fatores }\end{array}$ & $\begin{array}{c}\text { Raízes } \\
\text { características }\end{array}$ & $\begin{array}{c}\text { Variância } \\
\mathbf{( \% )}\end{array}$ & $\begin{array}{c}\text { Variância } \\
\text { Acumulada (\%) }\end{array}$ & $\begin{array}{c}\text { Conceito expresso } \\
\text { pelo fator }\end{array}$ \\
\hline 1 & $\mathrm{X} 1, \mathrm{X} 2, \mathrm{X} 3, \mathrm{X} 4, \mathrm{X} 5, \mathrm{X} 6, \mathrm{X} 7$ & 10,14 & 59,64 & 59,64 & Pobreza \\
\hline 2 & $\mathrm{X} 8, \mathrm{X} 9, \mathrm{X} 10, \mathrm{X} 11$ & 2,48 & 14,58 & 74,22 & Grau de ruralização \\
\hline 3 & $\mathrm{X} 12, \mathrm{X} 13, \mathrm{X} 14, \mathrm{X} 15$ & 1,15 & 8,33 & 82,55 & Educação superior \\
\hline 4 & $\mathrm{X} 16, \mathrm{X} 17$ & 1,10 & 6,47 & $89 . \ldots 2$ & Mulher
\end{tabular}

Fonte: Elaboração própria com base no programa SPSS 11.5.

\section{Tabela 4_Matriz de componentes após rotação varimax}

\begin{tabular}{|c|c|c|c|c|}
\hline \multirow{2}{*}{ Variáveis } & \multicolumn{4}{|c|}{ Fatores } \\
\hline & 1 & 2 & 3 & 4 \\
\hline População residente feminina (X17) & & & & 0,9070 \\
\hline Eleitores do sexo feminino (X16) & & & & 0,9330 \\
\hline Instituições de ensino superior (X12) & & & 0,6470 & \\
\hline Concluintes de ensino superior (X13) & & & 0,8660 & \\
\hline Matriculados em ensino superior (X14) & & & 0,8500 & \\
\hline Docentes per capita (X15) & & & 0,8220 & \\
\hline Pessoas com menos de 4 anos de estudo (X2) & 0,8010 & & & \\
\hline Analfabetos adultos (X1) & 0,8380 & & & \\
\hline IDH $(\mathrm{X} 7)$ & $-0,8740$ & & & \\
\hline Pessoas indigentes (X3) & 0,8710 & & & \\
\hline Pessoas pobres $(\mathrm{X} 4)$ & 0,8620 & & & \\
\hline Renda familiar inferior a 1 salário mínimo (X5) & 0,7560 & & & \\
\hline Índice de gini (X6) & 0,7060 & & & \\
\hline PEA rural (X9) & & 0,8420 & & \\
\hline População ocupada rural (X10) & & 0,8320 & & \\
\hline Capital residencial rural (X11) & & 0,8670 & & \\
\hline População rural (X8) & & 0,8110 & & \\
\hline
\end{tabular}

Fonte: Elaboração própria com base no programa SPSS 11.5. 
A outra forma é mediante a incorporação da dependência espacial na estrutura de erro. Esse é o modelo de erro espacial, adequado para correção de vieses introduzidos pela autocorrelação espacial, em razão do uso de dados espaciais. "grau de ruralização". Os fatores três e quatro foram denominados "educação superior" e "mulher", tendo em vista as variáveis que o definem.

A quarta etapa foi o cálculo da matriz de escores fatoriais, que servem para indicar a posição relativa de cada município em relação ao conceito expresso pelo fator ou como insumos nas regressões da próxima seção. Nelas, as variáveis independentes serão classificadas de acordo com esses conceitos.

\section{3_Econometria espacial}

Esta seção segue Anselin (1999), que sugere incorporar a dependência espacial no modelo de regressão linear padrão através da adição de um regressor na forma de uma variável dependente defasada espacialmente. ${ }^{7}$ De acordo com Anselin e Bera (1998), o modelo de defasagem espacial é formalmente apresentado por

$y=\rho W y+X \beta+\varepsilon$

em que:

- y é um vetor de observações para variável dependente, isto é, a taxa média de suicídio entre 1998-2002;

- Xé um vetor de variáveis explicativas (exógenas), que são fatores derivados da seção anterior, a saber: "pobreza”, "grau de ruralização", "educação superior" e "mulher", além da inclusão de dummies macrorregionais;

$-\varepsilon$ é o vetor $\mathrm{N} \times 1$ do termo de erros;

- $\rho$ é o parâmetro autorregressivo espacial, que mede a influência média dos vizinhos sobre observações no vetor $y$, indicando a proporção da variação total em y explicada pela dependência espacial;

- $\beta$ é o vetor $K \times 1$ de coeficientes de regressão; e

- Wy é o termo de defasagem espacial, que é correlacionado com os distúrbios, mesmo quando esses são independentes e identicamente distribuídos.

Mais detalhes sobre o método de estimação, como funcionam e como são construídos os testes de diagnóstico espacial podem ser vistos em Anselin (1992 e 1995).

A Tabela 5 mostra os resultados obtidos pelo método dos mínimos quadrados ordinários (MQO), como primeira tentativa de modelar o comportamento do suicídio no Brasil. Tal tabela é dividida em três partes. Na primeira, mostram-se os coeficientes estimados, seus 
Tabela 5_ Regressão por MQO e testes de diagnóstico para dependência espacial para taxa média de suicídio (1998-2002) no Brasil

\begin{tabular}{|c|c|c|c|c|}
\hline Variáveis Independentes & Coeficiente & Desvio Padrão & $\mathbf{t}$ & Probabilidade \\
\hline Constante & 10,9996 & 0,6301 & 17,4559 & 0,0000 \\
\hline Pobreza & $-3,9569$ & 0,4919 & $-8,0435$ & 0,0000 \\
\hline Grau de ruralização & 0,3391 & 0,3155 & 1,0749 & 0,2829 \\
\hline Educação superior & 0,8320 & 0,3058 & 2,7203 & 0,0067 \\
\hline Mulher & 0,4179 & 0,4094 & 1,0207 & 0,3078 \\
\hline Sul & 11,4930 & 0,9104 & 12,6240 & 0,0000 \\
\hline Centro-Oeste & 9,1780 & 1,1433 & 8,0274 & 0,0000 \\
\hline Norte & 0,3303 & 1,1961 & 0,2762 & 0,7825 \\
\hline Nordeste & 0,9940 & 1,2156 & 0,8177 & 0,4139 \\
\hline $\mathrm{R}^{2}$ (ajustado) & 0,5563 & Akaike & $3.678,38$ & \\
\hline Condição de multicolinearidade & 5,1774 & Schwarz & $3.717,30$ & \\
\hline Jarque-Bera & 31,23 & $* * *$ & & \\
\hline Koenker-Basset & 51,065 & $* * *$ & & \\
\hline Moran & 13,3548 & - & - & 0,0000 \\
\hline LM (erro) & 160,3606 & - & - & 0,0000 \\
\hline LM robusto (erro) & 2,6428 & - & - & 0,1040 \\
\hline LM (lag) & 169,2906 & - & - & 0,0000 \\
\hline LM robusto (lag) & 11,5728 & - & - & 0,0007 \\
\hline LM (SARMA) & 171,9334 & - & - & 0,0000 \\
\hline
\end{tabular}

*** Significativo a $1 \%$.

Fonte: Elaboração própria com base no programa SpaceStat 1.91.

Obs.: N = 558; Variável Dependente: Taxa Média de Suicídio entre 1998-2002.

desvios padrões, as estatísticas t e o valor de probabilidade. Na segunda, apresentam-se os testes para normalidade dos erros e heterocedasticidade, o indicador de multicolinearidade, o grau de ajuste do modelo e os critérios de informação. $\mathrm{Na}$ terceira, encontram-se os testes de diagnóstico para dependência espacial.
A segunda parte da Tabela 5 mostra que o grau de ajuste do modelo é de $56 \%$ e que, pela averiguação do teste Jarque-Bera, os erros não são distribuídos normalmente. Ademais, há evidências de heterocedasticidade, por meio do teste de Koenker-Bassett, já que o valor da estatística é significativo a $1 \%$, rejeitan- 
8 Embora seja realizada essa interpretação simplificada do significado da variável dependente defasada espacialmente do modelo expresso na forma reduzida da equação (1), há que se ressaltar, com base em Anselin (2003), que tal variável reflete, de fato, um padrão espacial particular entre as regiões e suas respectivas vizinhanças. Tal padrão, por sua vez, é resultante do equilíbrio entre a correlação espacial global das variáveis independentes e a dos termos de erro. do a hipótese nula de homoscedasticidade. Por outro lado, não há indicação de problema de multicolinearidade graças à realização de uma análise fatorial para as variáveis independentes. Ademais, há fortes sinais de que os erros sejam autocorrelacionados espacialmente, valendose do resultado do I de Moran.

O problema do I de Moran é que, quando estatisticamente significativo, não fornece indicações sobre a forma da autocorrelação espacial presente. Os testes do tipo Multiplicador de Lagrange (ML), apresentados na última parte da Tabela 5, têm a capacidade de especificar a forma assumida pela autocorrelação espacial. Para a seleção do modelo, foram seguidos os procedimentos de identificação proposto por Florax et al. (2002). Primeiro, os testes ML (erro) e ML (defasagem) mostraram-se significativos estatisticamente. Segundo, procedeu-se a análise das suas versões robustas. Nesse caso, a versão robusta do ML (defasagem) foi significativa. Com base nos passos acima citados, o modelo mais adequado foi o de defasagem espacial.

Em relação às variáveis independentes provenientes da análise fatorial, o primeiro ponto a ser observado na Tabela 5 é que, com exceção dos fatores que captam o grau de ruralização, a taxa de participação feminina e as dummies Norte e Nordeste, todos os demais coeficientes são altamente significativos. Entretanto, pela possibilidade de que os resultados do modelo estimado por MQO sejam inconsistentes e ineficientes, é preciso interpretá-los com base no modelo de defasagem espacial, estimado com desvios padrões corrigidos para permitir inferência robusta (Tabela 6 ).

A Tabela 6 mostra que as variáveis pobreza e grau de ruralização, além da variável dependente defasada espacialmente, são significativas e possuem coeficientes com sinal esperado. Outras variáveis que possuem coeficientes com sinal positivo e significativo são as dummies do Centro-Oeste e do Sul. Isso mostra que existem diferenças regionais relevantes nos índices de suicídio nacionais, indicando que o Centro-Oeste e o Sul possuem maiores taxas de suicídio que a região Sudeste, categoria de referência do estudo, conforme pôde ser constatado nas Figuras 2 e 3.

É importante ressaltar que a variável dependente defasada espacialmente confirma a hipótese de "efeito contágio" espacial, significando que taxas de suicídio dos vizinhos de uma microrregião devem ser consideradas entre os seus determinantes. ${ }^{8} \mathrm{O}$ método usado neste 
Tahela 6_Regressão por mínimos quadrados em dois estágios para taxa média de suicídio (1998-2002) no Brasil ${ }^{(a)}$

\begin{tabular}{|c|c|c|c|c|}
\hline Variáveis Independentes & Coeficiente & Desvio Padrão & $\mathbf{t}$ & Probabilidade \\
\hline Variável dependente defasada & 0,5414 & 0,1127 & 4,8046 & 0,0000 \\
\hline Constante & 5,2301 & 1,3814 & 3,7861 & 0,0002 \\
\hline Pobreza & $-2,0235$ & 0,5321 & $-3,8026$ & 0,0001 \\
\hline Grau de ruralização & 0,5755 & 0,3152 & 1,8256 & 0,0679 \\
\hline Educação superior & 0,2852 & 0,2713 & 1,0511 & 0,2932 \\
\hline Mulher & 0,3951 & 0,3408 & 1,1595 & 0,2462 \\
\hline Sul & 4,5907 & 1,6281 & 2,8196 & 0,0048 \\
\hline Centro-Oeste & 5,1369 & 1,2680 & 4,0512 & 0,0001 \\
\hline Norte & $-0,1920$ & 0,9743 & $-0,1970$ & 0,8438 \\
\hline Nordeste & $-0,1428$ & 0,9058 & $-0,1577$ & 0,8747 \\
\hline $\mathrm{R}^{2}$ (ajustado) & 0,6400 & & & \\
\hline
\end{tabular}

(a) Desvios - Padrões Corrigidos pelo Método de Estimação Robusto.

*** Significativo a $1 \%$.

Fonte: elaboração própria com base no programa SpaceStat 1.91.

Obs.: N = 558; Variável Dependente: Taxa Média de Suicídio entre 1998-2002.

artigo permite a constatação de que mecanismos de interação social, facilitados pela distância geográfica, exercem influência sobre as taxas de suicídio, o que foi inicialmente levantado por Durkheim, enfatizando que era necessária uma metodologia adequada para "mapear" o fenômeno. $\mathrm{O}$ resultado encontrado neste artigo sugere que as políticas públicas direcionadas ao enfrentamento do problema sejam contempladas numa escala maior que a local, visto que os casos são dependentes espacialmente.
A relação negativa entre o nível de pobreza da microrregião e a taxa de suicídio sugere que podem prevalecer no Brasil as razões apontadas pelas teorias sociológicas, ou seja, maiores níveis de renda aumentam a sensação de independência e degeneram a família como instituição social. No caso brasileiro, os resultados confirmam, a priori, a tese durkheimiana de "suicídio egoísta". É importante enfatizar que este artigo usa múltiplos indicadores que compõem o fator "pobreza". Ao se analisar casos 
internacionais, o uso de apenas um indicador para representar a situação econômica do país ou região, como a medida de desigualdade expressa pelo Índice de Gini, indica a existência de uma relação positiva entre taxas de suicídio e desigualdade, a exemplo dos casos de países europeus (Andrés, 2005) e da OCDE (Chen et al., 2007). Em que pesem às diferenças metodológicas, o caso brasileiro parece, portanto, mostrar uma realidade distinta.

A relação positiva entre grau de ruralização e taxas de suicídio indica que o difícil acesso à rede de saúde e de serviços em geral, o declínio econômico das áreas rurais e o uso de agrotóxicos, que desencadeiam quadros depressivos por mecanismos neurológicos ou endócrinos em lavradores, aumentam o risco de suicídio. Essa evidência empírica brasileira contraria a expectativa teórica, com base em Durkheim, na qual as taxas de suicídio são positivamente relacionadas com o grau de urbanização. Por outro lado, outras evidências empíricas internacionais, como os casos de Nova Jersey nos EUA (Hempstead, 2006), também constatam que os suicídios na área rural são maiores que na área urbana, em razão, possivelmente, do maior acesso a armas de fogo. Por outro lado, enquanto, no caso finlandês, Matti (1998) encontra associação positiva, Mitra e Shroff (2006) não constatam relacionamento estatístico significativo entre suicídio e urbanização, no estudo de estados da Índia.

O fator "mulher" não é significativo estatisticamente. Esse resultado não surpreende porque no Brasil, assim como no resto do mundo, a taxa de suicídio de mulheres é menor que a dos homens. No período em consideração (1998-2002), somente 24\% do número total de suicídios no Brasil são relativos a mulheres.

Outra variável com sinal positivo e não significativa é educação superior. A expectativa teórica de sinal positivo e significativo não é corroborada pela evidência empírica brasileira, embora houvesse os argumentos de que a maior escolaridade encoraja maior "sensação de liberdade" e de que está associada a cargos que envolvem mais estresse. Embora haja evidências internacionais favoráveis a essa relação positiva, como o caso de Taiwan, reportado por Lin (2006), a escolaridade superior, no Brasil, pode não ocasionar maior isolamento social nem a "sensação de liberdade" propiciada pelo curso superior seria tão relevante para conduzir ao ato suicida. Além disso, investigar o nível de complexidade e grau 
de "pressão" de ocupações/cargos, que envolvem escolaridade superior, poderia ser uma linha de pesquisa promissora.

Uma forma alternativa à estimação da Tabela 6, para resolver o problema da heterocedasticidade, é definir um regime espacial baseado numa variável categórica relacionada ao nível de escolaridade de pessoas acima de 25 anos, especificamente pessoas com pelo menos 11 anos de estudo, disponível no sítio do IPEA e referente ao ano de 2000. Dessa forma, dividiu-se a amostra de microrregiões em dois grupos, ou seja, metade da amostra possui os maiores percentuais de pessoas com mais de 11 anos de estudo, e a outra metade, os menores. Vale ressaltar que essa variável não foi usada anteriormente entre aquelas que definiram o fator educação superior e que representa, grosso modo, qualificação média das pessoas residentes na microrregião. Nos indicadores que representam o fator educação superior, a base de comparação dos concluintes e dos matriculados no ensino superior é a população jovem. A teoria também corrobora a escolha dessa variável categórica, uma vez que o nível de instrução do indivíduo é positivamente relacionado ao suicídio. Os regimes espaciais serão validados pelo teste de quebra estrutural de Chow.
A Tabela 7 apresenta os resultados do modelo de defasagem com regimes espaciais por mínimos quadrados em dois estágios (MQ2E). Ressalta-se que a estatística de Chow se mostrou altamente significativa, rejeitando a hipótese nula de que os coeficientes são iguais para o conjunto de microrregiões brasileiras. Essa instabilidade estrutural nos coeficientes confirma a existência de dois regimes espaciais no Brasil. Se tomarmos os coeficientes individualmente, apenas a constante, o fator mulher e as dummies (exceto a da macrorregião Norte) são estáveis nos dois regimes. Por outro lado, os fatores pobreza, grau de ruralização e educação superior são instáveis estruturalmente ao nível de significância de $1 \%$, para as duas primeiras, e $5 \%$, para a terceira.

As microrregiões que têm maior percentual de pessoas com mais de 11 anos de estudo possuem coeficientes com nome seguidos de 1 como sufixo. As microrregiões situadas no outro grupo possuem sufixo 0 . No caso destas, apenas a constante, o fator pobreza e a dummy do Centro-Oeste são significativas. Naquelas, a constante, o grau de ruralização, o fator educação superior e as dummies Centro-Oeste e Norte são estatisticamente significativas, com destaque 
Tabela 7 Modelo de defasagem heterocedástico para taxa média de suicídio (1998-2002) no Brasil: estimação por mínimos quadrados em dois estágios

\begin{tabular}{|c|c|c|c|c|}
\hline Variáveis Independentes & Coeficiente & Desvio-Padrão & $\mathbf{t}$ & Probabilidade \\
\hline Variável dependente defasada & 0,6721 & 0,1172 & 5,7342 & 0,0000 \\
\hline Constante_0 & 4,9311 & 1,7328 & 2,85 & 0,0044 \\
\hline Pobreza_0 & $-2,7484$ & 0,7111 & $-3,86$ & 0,0001 \\
\hline Grau de Ruralização_0 & $-0,1889$ & 0,4844 & $-0,39$ & 0,6965 \\
\hline Educação Superior_0 & 2,0116 & 1,2917 & 1,56 & 0,1194 \\
\hline Mulher_0 & 0,2630 & 0,5167 & 0,51 & 0,6107 \\
\hline Sul_0 & 1,0932 & 2,4991 & 0,44 & 0,6618 \\
\hline Centro-Oeste_0 & 3,7725 & 2,0051 & 1,88 & 0,0599 \\
\hline Norte_0 & $-1,1119$ & 1,4318 & $-0,78$ & 0,4374 \\
\hline Nordeste_0 & 0,7805 & 1,3416 & 0,58 & 0,5607 \\
\hline Constante_1 & 5,6166 & 1,7500 & 3,21 & 0,0013 \\
\hline Pobreza_1 & $-0,3824$ & 0,8332 & $-0,46$ & 0,6463 \\
\hline Grau de Ruralização_1 & 2,1444 & 0,5177 & 4,14 & 0,0000 \\
\hline Educação Superior_1 & $-0,6747$ & 0,3510 & $-1,92$ & 0,0546 \\
\hline Mulher_1 & 0,5598 & 0,5356 & 1,05 & 0,2959 \\
\hline Sul_1 & 1,9995 & 1,6129 & 1,24 & 0,2151 \\
\hline Centro-Oeste_1 & 3,9306 & 1,5199 & 2,59 & 0,0097 \\
\hline Norte_1 & 5,4653 & 1,8409 & 2,97 & 0,0030 \\
\hline Nordeste_1 & 1,2530 & 1,7516 & 0,72 & 0,4744 \\
\hline \multicolumn{5}{|c|}{ Estabilidade dos Coeficientes Individuais } \\
\hline Constante_0 & 0,1730 & - & - & 0,6774 \\
\hline Pobreza_0 & 5,4734 & - & - & 0,0193 \\
\hline Grau de Ruralização_0 & 10,3050 & - & - & 0,0013 \\
\hline Educação Superior_0 & 4,1085 & - & - & 0,0427 \\
\hline Mulher_0 & 0,1590 & - & - & 0,6901 \\
\hline Sul_0 & 0,1780 & - & - & 0,6731 \\
\hline Centro-Oeste_0 & 0,0055 & - & - & 0,9407 \\
\hline Norte_0 & 7,9729 & - & - & 0,0047 \\
\hline Nordeste_0 & 0,0449 & - & - & 0,8321 \\
\hline $\mathrm{R}^{2}$ (ajustado) & 0,6829 & & & \\
\hline Chow - Wald & 32,9773 & $* * *$ & 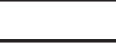 & \\
\hline ML (lag) ...... & 2,5689 & $-\ldots$ & $-\ldots$ & 0,1090 \\
\hline
\end{tabular}


para o fator grau de ruralização que possui maior coeficiente.

Essas evidências mostram que microrregiões com população de menor escolaridade (coeficientes com sufixo 0) possuem forte associação negativa entre a pobreza e os casos de suicídio, se constatadas a magnitude e a significância do coeficiente. Esse fato não ocorre nas microrregiões de maior escolaridade (sufixo 1), pois o fator pobreza, embora negativo, não é significativamente diferente de zero. Esse resultado está associado ao artifício de dividir a amostra em dois grupos, o que concentrou microrregiões muito pobres no primeiro grupo (sufixo 0), validando a relação negativa entre pobreza e taxa de suicídio, encontrada na Tabela 6, apenas para essa parte da amostra.

Nas microrregiões com maior escolaridade (sufixo 1), o fator que mais contribui para explicar a taxa de suicídio é o grau de ruralização, significativo e positivo. Nota-se, portanto, que os suicídios ocorrem em regiões com perfis eminentemente rurais e com boas taxas de escolaridade. O outro fator relevante para explicar o suicídio é a educação superior, que apresentou sinal negativo, contrariando a expectativa teórica. Portanto, os resultados indicam que no grupo formado pelas microrregiões com maior participação de pessoas com mais de 11 anos de estudo no total da população, o fator educação superior se mostra negativamente relacionado à taxa de suicídio. Como se trata de um grupo de microrregiões que já possui melhores taxas de qualificação média da população, o sinal negativo para essa variável leva a crer que o problema do suicídio é mais frequente entre as microrregiões cujo fator educação superior se situa em nível mediano, entre as microrregiões com maior valor para esse fator e aquelas que pertencem ao grupo de sufixo zero. Além disso, as macrorregiões Norte e CentroOeste, ao contrário da Sul cuja dummy é não significativa, destacam-se em relação ao Sudeste.

Embora não possa ser visto na Tabela 7, o problema da heterocedasticidade (constatado na Tabela 5) pôde ser solucionado a partir da divisão da amostra em dois grupos. O Anexo contém a estimação do método de MQO com dois regimes. Nele, é possível observar que o teste de Koenker-Basset não é significativo estatisticamente. 


\section{5_Conclusões e sugestão de políticas públicas}

Atualmente, a busca de novos paradigmas para o campo da saúde coletiva deve ser acompanhada pelo desenvolvimento de métodos que incorporem a dimensão do lugar, como expressão da dinâmica social do espaço. A compreensão do conteúdo geográfico tem grande potencial não só explicativo, como também da identificação de situações-problema para a saúde, e com base nisso, de planejamento e de organização das ações.

O objetivo deste artigo foi o de avaliar os determinantes socioeconômicos do suicídio no Brasil, levando em conta os aspectos espaciais, como a dependência e a heterogeneidade. $\mathrm{O}$ primeiro aspecto foi abordado com a inclusão de uma variável dependente defasada que se mostrou altamente significativa. Isso quer dizer que a hipótese de "efeito contágio" espacial pode ser confirmada a partir da amostra de microrregiões geográficas brasileiras. A própria análise exploratória indicou forte associação espacial global da taxa média de suicídio do período 1998-2002, tendo em vista que o valor positivo para a estatística $I$ de $M o$ ran apontou autocorrelação espacial positiva. O segundo aspecto foi enfrenta- do com a divisão das microrregiões em dois grupos, de acordo com a participação de pessoas muito educadas no total da população, tendo em vista as sugestões da literatura que indicam existir uma relação entre escolaridade e propensão ao suicídio.

Além da taxa de suicídio dos vizinhos, os determinantes do suicídio são a pobreza e o grau de ruralização. O primeiro é negativamente relacionado, enquanto no segundo constata-se uma relação direta entre ruralização da microrregião e taxas de suicídio. Essas evidências corroboram a tese de Durkheim de suicídio egoísta, já que a violência contra a própria vida acontece em microrregiões com baixo grau de pobreza, além de ser mais frequente em ambientes rurais e não em cidades. Esse segundo resultado não confirma aquele encontrado pelo sociólogo, que caracterizava o suicídio como fenômeno urbano.

O fator "mulher" na sociedade nunca se mostrou relevante, impedindo que se alcancem conclusões semelhantes à literatura internacional. A educação superior nem sempre foi fator relevante na explicação do suicídio, e, algumas vezes, mostrou-se com sinal contrário ao esperado. Todos os determinantes mencionados foram resultantes de técnica de 
análise multivariada que condensou muitos dos indicadores que a literatura sempre aponta como importantes causadores do problema estudado.

Este artigo possui duas linhas de sugestões de políticas públicas. Na primeira, recomenda-se a criação de um plano nacional de prevenção ao suicídio que objetive sensibilizar a sociedade e mostrar que o suicídio não está limitado ao indivíduo, mas sim relacionado à sociedade como um todo. Outra estratégia é investir em políticas de cuidados integrados que incluam a garantia de acesso às diversas modalidades de terapia, a promoção de qualidade de vida e a prevenção de danos.

A intensificação de campanhas de valorização da vida e maior atenção a problemas mentais, psicológicos e psiquiátricos poderiam aliviar o problema nas microrregiões com índices de suicídio mais expressivos. Por outro lado, como há evidências de que o suicídio é um problema com maior expressão em áreas rurais, possivelmente agravado pelo uso de agrotóxicos, é também necessário haver melhor regulamentação desse tipo de substância.

Como segunda sugestão de política pública, deveria haver melhorias nos sistemas de informação sobre o suicídio e a promoção do intercâmbio dessas informações. Investir na educação permanente de profissionais da saúde é outro fator fundamental para identificar um comportamento suicida, sendo um importante mecanismo de prevenção.

Os padrões espaciais identificados neste trabalho servem de base para futuras especificações econométricas que tornem explícitos os determinantes regionais do suicídio no Brasil, levando em conta fatores socioeconômicos. Isso permitiria um mapeamento dos fatores de risco e situações que antecedem o ato suicida, favorecendo a compreensão do fenômeno no país e o desenvolvimento de estratégias mais eficazes para a prevenção do suicídio. 


\section{Referências bibliográficas}

ANDRÉS, A. Income inequality, unemployment, and suicide: a panel data analysis of 15 European countries. Applied Economics, v. 37, p. 439-451, 2005.

ANSELIN, L.; BERA, A. Spatial dependence in linear regression models with an introduction to spatial econometrics. In: ULLAH, A.; GILES, D. E. A. (Eds.).

Handbook of applied economic statistics. Nova York: Marcel Dekker, 1998. p. 237-289.

ANSELIN, L. SpaceStat tutorial: a workbook for using SpaceStat in the analysis of spatial data. Urbana-Champaign: University of Illinois, 1992.

ANSELIN, L. SpaceStat version 1.80 user's guide. Urbana-Champaign: University of Illinois, 1995a.

ANSELIN, L. Spatial econometrics. School of Social Science, University of Texas, Dallas, 1999.

ANSELIN, L. Local indicators of spatial association-LISA. Geographical Analysis, v. 27, p. $93-115,1995 \mathrm{~b}$.

ANSELIN, L. Spatial externalities, spatial multipliers and spatial econometrics. International Regional Science Review, v. 26, n. 2, p. 153-66, 2003.
BILLS, C.; LI, G. Correlating homicide and suicide. International Journal of Epidemiology, v. 34, p. $837-845,2005$.

BRANDÃO, A. Psicopatologia: suicídio. Centro Federal de Educação Tecnológica de São Paulo. Disponível em: $<$ http:// www.cefetsp.br/edu/ sinergia/5p9c.html>.

Acesso em: 5 jan. 2008.

CERQUEIRA, D. R. C.; CARVALHO, A. X. Y.; LOBÃO, W. J. A.; RODRIGUES, R. I. Análise dos custos e conseqüencias da violência no Brasil. Brasília: IPEA, 2007. (Texto para

Discussão, 1284).

CHEN, J.; CHOI, Y.; SAWADA, $\mathrm{Y}$. How is suicide different in Japan? Japão, 2007. (Working Paper, CIRJE-F-526).

CHUANG, H; HUANG, W. A reexamination of sociological and economic theories os suicide: a comparison of the U.S.A. and Taiwan. Social Science \& Medicine, v. 43, p. 421-423, 1996.

CHUANG, H.; HUANG, W.

Economic and social correlates of regional suicide rates: a pooled cross-section and time-series analysis. Journal of Socio-Economics, v. 26, p. 277-289, 1997.
CUTLER, D.; GLAESER, E.; NORBERG, K. Explaining the rise in youth suicide. National Bureau of Economic Research - NBER. Cambridge, 2000. (Working Paper, 7713).

DÍAZ, E.; BARRÍA, R. Suicidio y Producto Interno Bruto (PIB) en Chile: hacia un modelo predictivo. Revista Latinoamericana de Pisicologia, v. 2, p. 343-359, 2006.

DURKHEIM, E. O suicídio. São Paulo: Martin Claret, 2003.

FLORAX, R.; FOLMER, H.; REY, S. Specification searches in spatial econometrics: the relevance of Hendry's methodology.

Department of Spatial Economics, Free University Amsterdam, 2002. (Working Paper).

GUNNELL, D.; LOPATATZIDIS, A.; DORLING, D.; WEHNER, H.; SOUTHALL H.; FRANKEL

E. Suicide and unemployment in young people: analysis of trends in England and Wales, 1921-32 1995. The Journal of Mental Science, v. 175, p. 263-270, 1999.

HAMERMESH, D.; HOSS, N. An economic theory of suicide. The Journal of Political Economy, v. 82, p. 83-98, 1974.
HEMPSTEAD, K. The geography of self-injury: spatial patterns in attempted and completed suicide. Social Science \& Medicine, v. 62, p. 3186-3196, 2006.

IBGE. Base de informações municipais. 3. ed. Rio de Janeiro: IBGE, 2002 (CD-ROM).

INEP/MEC. Sistema de Estatísticas Educacionais. Disponível em: $<$ http://www.ipeadata.gov.br $>$. Acesso em: 5 jan. 2008.

INOUE, K.; TANNI, H.; ABE, S. The correlation between rates of unemployment and suicides rates in Japan between 1984 and 2003. Journal of Forensic and Legal Medicine, v. 14, p. 238-239, 2007.

IPEA. Custo da violência para o sistema público de saúde no Brasil. 2007. (Texto para discussão, 1295).

IPEA. Dados sobre suicídio, educação, população e desigualdade. 2008. Disponível em: < http://www. ipeadata.gov.br $>$. Acesso em: 2 out. 2009.

KAPLAN, H. I.; SADOCK, B. J.; GREEB, J. A. Compêndio de psiquiatria - ciências do comportamento e psiquiatria clínica. 7. ed. Porto Alegre: Artes Médicas, 1997. 
KOO, J.; COX, W. An economic interpretation od suicide gycles in Japan. Federal Reserve Bank of Dallas. Dallas, 2006. (Working

Paper, 0603).

KRUG, E.; KRESNOW, M.; PEDDICORD, J.; DAHLBERG, L.; POWELL, K.; CROSBY, A.; ANNEST, J. Suicide after natural disasters. The New England Journal of Medicine, v. 338, p. 373-378, 1998.

LIN, S. Unemployment and suicide: panel data analyses. The Social Science Journal, v. 43, p. $727-732,2006$

LUCEY, S.; CORCORAN, P.; KEELEY, H. S.; BROPHY, J.; ARENSMAN, E.; PERRY, I. J. Socioeconomic change and suicide: a time-series study from the Republic of

Ireland. Crisis, v. 26, n. 2, p. [UTF-8?]90-94, 2005.

MANLY, B. Multivariate statistical methods: a primer. London: Chapman and Hall Ltd., 1986.

MATTI, V. Testing the "natural rate of suicide" bypothesis. VAT"T (Government Institute for Economic Research). Finland, 1998.

MENEGHEL, S.; VICTORA, C.; FARIA, N.; CARVALHO, A.; FALK, J. Características epidemiológicas do suicídio no Rio Grande do Sul. Revista de Saúde Pública, v. 38, p. 804-810, 2004.
MIDDLETON, N.; GUNNELL, D.; FRANKEL, S.; WHITLEY, E.; DORLING, D. Urban-rural differences in suicide trends in young adults: England and Wales, 1981-1998. Social Science \& Medicine, v. 57, p. 1183-1194, 2003.

MINOIU, C.; ANDRÉS, A. The effect od public spending on suicide: evidence from US state data. Journal of Socio-Economics, v. 37, p. 237-261, 2006.

\section{MITRA, S.; SHROFF, S.}

Determinants of suicide rates in developing countries: an econometric investigation of the Indian case. India, Jadavpur University, 2004 (Discussion Paper).

MITRA, S.; SHROFF, S.

\section{Determinants of suicide rates in} developing countries: an econometric investigation of the Indian case. Jadavpur University: India, 2006. (Working Paper).

MORRELL, S.; PAGEB, A.; TAYLORB, R. The decline in Australian young male suicide. Social Science \& Medicine, v. 64, p. 747-754, 2007.

\section{OLIVEIRA, D. Freqüência de} suicídios registrados pelo Instituto Médico Legal de Palmas-Tocantins perfil das vitimas. Tocantins, UFT, 2004.

(Monografia).

ORGANIZAÇÃO MUNDIAL DE SAÚDE (OMS). Dados sobre suicidio para diversos países. Disponível em: <http://www. who.int>. Acesso em: 2 jan. 2008.
ORGANIZAÇÃO MUNDIAL DE SAÚDE (OMS). Prevenção do suicídio: um manual para médicos clínicos gerais. Genebra, 2000. 18p.

PEREIRA, J. Análise de

dados qualitativos: estratégias metodológicas para as ciências da saúde, humanas e sociais. São Paulo: EDUSP, 1999.

PIRES, D.; CALDAS, E.; RECENA, M. Uso de agrotóxicos e suicídios no Estado do Mato Grosso do Sul, Brasil. Caderno de Saúde Pública. Rio de Janeiro, v. 21, p. 598-605, 2005.

PROGRAMA DAS

NAÇÕES UNIDAS PARA O DESENVOLVIMENTO (PNUD). Atlas do desenvolvimento bumano no Brasil. Disponível em: $<$ http://www.pnud.org.br/ atlas/>. Acesso em: 4 jan. 2008.

RODRÍGUEZ, A. Inequality and duicide rates: A cross-country study. institute for advanced development studies. Chile, 2006. (Working Paper, 13).

SHIKIDA, C.; GAZZI, R.; JUNIOR, A. Teoria econômica do suicídio: estudo empírico para o Brasil. Belo Horizonte: IBMEC/ MG, 2006. (Working Paper, WP39).

SHOAF, K.; SAUTER, C.; BOURQUE, L.; GIANGRECO, C.; WEISS, B. Suicides in Los Angeles county in relation to the Northridge Earthquake. Prehospital and Disaster Medicine, v. 19, p. 309-310, 2004.
SWISSINFO. Suicídios custam caro à sociedade. Disponível em: < http:/ / www.swissinfo.ch/por/swissinfo.h tml? siteSect $=105 \&$ sid $=4231350>$. Acesso em: 7 fev. 2008.

VALÉRIO, M. Álcool e suicídio. Pós-Graduação em Intervenção Social. Portugal: Vila Nova de Gaia, 2006. (Working paper).

WATANABE, R.; FURUKAWA, M.; NAKAMURA, R.; OGURA,

Y. Analysis of the socioeconomic difficulties affecting the suicide rate in Japan. Kyoto Institute of Economic Research. Japão, 2006. (Working Paper, 626).

\section{E-mail de contato do autor:}

udmilla.costa@ufif.edu.br

eduardo.goncalves@uff.edu.br

oliveira.junior@uff.edu.br

2010;

aprovado em Agosto de 2010. 
Tabela 1_ Regressão por mínimos quadrados ordinários com regimes espaciais para taxa média de suicídio (1998-2002) no Brasil

\begin{tabular}{|c|c|c|c|c|}
\hline & & & & ICOntinu \\
\hline Variáveis Independentes & Coeficiente & Desvio-Padrão & $\mathbf{t}$ & Probabilidade \\
\hline Constante_0 & 11,1275 & 1,1842 & 9,3963 & 0,0000 \\
\hline Pobreza_0 & $-4,2386$ & 0,6957 & $-6,0924$ & 0,0000 \\
\hline Grau de Ruralização_0 & $-0,5450$ & 0,4856 & $-1,1224$ & 0,2622 \\
\hline Educação Superior_0 & 2,5346 & 1,1960 & 2,1193 & 0,0345 \\
\hline Mulher_0 & 0,6413 & 0,5414 & 1,1846 & 0,2367 \\
\hline Sul_0 & 12,5346 & 1,7306 & 7,2430 & 0,0000 \\
\hline Centro-Oeste_0 & 9,9630 & 1,6880 & 5,9022 & 0,0000 \\
\hline Norte_0 & 0,3205 & 1,4790 & 0,2167 & 0,8285 \\
\hline Nordeste_0 & 2,0243 & 1,4091 & 1,4366 & 0,1514 \\
\hline Constante_1 & 16,9374 & 1,3523 & 12,5250 & 0,0000 \\
\hline Pobreza_1 & $-1,3300$ & 1,0195 & $-1,3046$ & 0,1926 \\
\hline Grau de Ruralização_1 & 4,5789 & 0,7494 & 6,1103 & 0,0000 \\
\hline Educação Superior_1 & $-0,8975$ & 0,4698 & $-1,9101$ & 0,0566 \\
\hline Mulher_1 & 0,0019 & 0,6790 & 0,0028 & 0,9978 \\
\hline Sul_1 & 8,5195 & 1,1243 & 7,5774 & 0,0000 \\
\hline Centro-Oeste_1 & 8,2870 & 1,5878 & 5,2193 & 0,0000 \\
\hline Norte_1 & 5,4330 & 2,3635 & 2,2988 & 0,0219 \\
\hline Nordeste_1 & 0,4823 & 2,2414 & 0,2152 & 0,8297 \\
\hline Estabilidade dos Coeficientes Inc & & & & \\
\hline Constante_0 & 10,4469 & - & - & 0,0013 \\
\hline Pobreza_0 & 5,5537 & - & - & 0,0188 \\
\hline Grau de Ruralização_0 & 32,9267 & - & - & 0,0000 \\
\hline Educação Superior_0 & 7,1342 & - & - & 0,0078 \\
\hline Mulher_0 & 0,5421 & - & - & 0,4619 \\
\hline Sul_0 & 3,7852 & - & - & 0,0522 \\
\hline Centro-Oeste_0 & 0,5230 & - & - & 0,4699 \\
\hline Norte_0 & 3,3625 & - & - & 0,0672 \\
\hline Nordeste_0 & 0,3392 & - & - & 0,5605 \\
\hline R2 (ajustado) & 0,5865 & Akaike & $3.647,84$ & \\
\hline Condição de Multicolinearidade & 7,4682 & Schwarz & $3.725,68$ & \\
\hline Jarque-Bera & 59,8787 & - & & \\
\hline Koenker-Basset & 0,0113 & NS & & \\
\hline Teste de Chow & 5,4533 & $-\ldots$ & & \\
\hline
\end{tabular}


Tabela 1_Regressão por mínimos quadrados ordinários com regimes espaciais para taxa média de suicídio (1998-2002) no Brasil

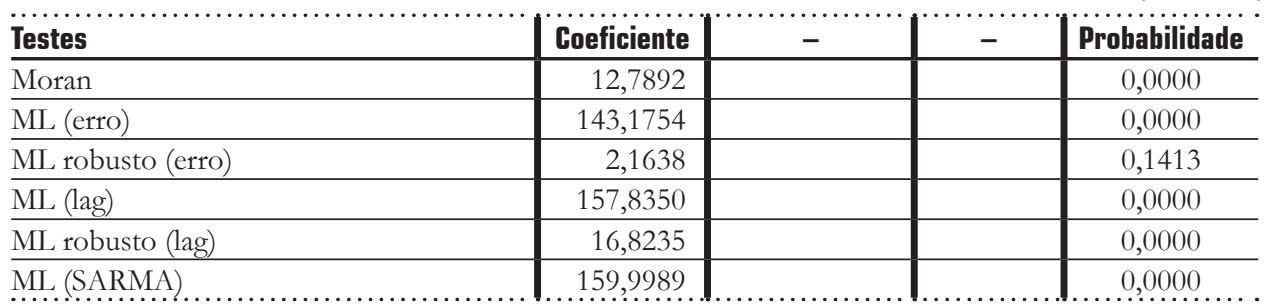

NS = Não Significativo; $* * *$ Significativo a $1 \%$

Fonte: Elaboração própria com base no programa SpaceStat 1.91.

Obs.: N = 558; Variável Dependente: Taxa Média de Suicídio entre 1998-2002. 